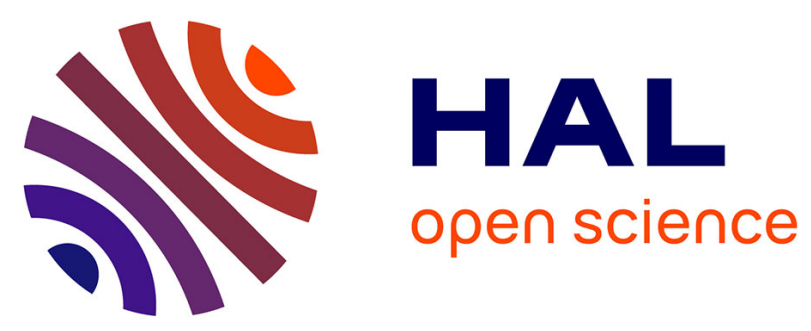

\title{
Redox- and solvato-magnetic switching in a tetrathiafulvalene-based triad single-molecule magnet
}

Fabrice Pointillart, Jessica Flores Gonzalez, Vincent Montigaud, Lorenzo Tesi,

Vladimir K. Cherkasov, Boris Le Guennic, Olivier Cador, Lahcène Ouahab, Roberta Sessoli, Viacheslav Kuropatov

\section{To cite this version:}

Fabrice Pointillart, Jessica Flores Gonzalez, Vincent Montigaud, Lorenzo Tesi, Vladimir K. Cherkasov, et al.. Redox- and solvato-magnetic switching in a tetrathiafulvalene-based triad single-molecule magnet. Inorganic Chemistry Frontiers, 2020, 7 (12), pp.2322-2334. 10.1039/d0qi00319k . hal-02928529

\section{HAL Id: hal-02928529 \\ https://hal.science/hal-02928529}

Submitted on 22 Feb 2021

HAL is a multi-disciplinary open access archive for the deposit and dissemination of scientific research documents, whether they are published or not. The documents may come from teaching and research institutions in France or abroad, or from public or private research centers.
L'archive ouverte pluridisciplinaire HAL, est destinée au dépôt et à la diffusion de documents scientifiques de niveau recherche, publiés ou non, émanant des établissements d'enseignement et de recherche français ou étrangers, des laboratoires publics ou privés. 


\section{Redox- and Solvato-Magnetic Switching in a Tetrathiafulvalene-}

\section{Based Triad Single-Molecule Magnet}

Fabrice Pointillart, ${ }^{* a}$ Jessica Flores Gonzalez, ${ }^{a}$ Vincent Montigaud, ${ }^{a}$ Lorenzo Tesi, ${ }^{\mathrm{b}, \mathrm{c}}$ Vladimir Cherkasov, ${ }^{d}$ Boris Le Guennic, ${ }^{a}$ Olivier Cador, ${ }^{a}$ Lahcène Ouahab, ${ }^{a}$ Roberta Sessoli ${ }^{b}$ and Viacheslav Kuropatov*d

\footnotetext{
a. Univ Rennes, CNRS, ISCR (Institut des Sciences Chimiques de Rennes) - UMR 6226,

F-35000 Rennes, France.

b. Dipartimento di Chimica "Ugo Schiff" \& INSTM RU, Università degli Studi di

Firenze, Via della Lastruccia 3-13, I50019 Sesto Fiorentino (Firenze), Italy.

c. Institute of Physical Chemistry, University of Stuttgart, Pfaffenwaldring 55, 70569,

Stuttgart, Germany.

d. G. A. Razuvaev Institute of Organometallic Chemistry of Russian Academy of

Sciences, 603950, GSP-445, Tropinina str., 49, Nizhny Novgorod, Russia.
}

The first simultaneous redox and solvato-magnetic switching was achieved. The dinuclear complex $\left[\mathrm{Dy}_{2}(\mathrm{hfac})_{6}\left(\mathrm{H}_{2} \mathrm{SQ}\right)\right] \cdot \mathrm{CH} \mathrm{Cl}_{2}\left(\mathrm{Dy} \mathrm{H}_{2} \mathrm{SQ}\right)($ where $\mathrm{hfac}=$ 1,1,1,5,5,5-hexafluoroacethylacetonate and $\mathrm{H}_{2} \mathrm{SQ}=$ 2,2'-benzene-1,4-diylbis(6-hydroxy-4,7-di-tert-butyl-1,3-benzodithiol-2-ylium-5-olate) was reversibly oxidized into the dinuclear complex $\left[\mathrm{Dy}_{2}(\mathrm{hfac})_{6}\left(\mathrm{H}_{2} \mathrm{O}\right)_{2}(\mathbf{Q})\right]$ (Dy2 $\left.\mathbf{Q}\right)$ (where $\mathbf{Q}=2,2^{\prime}$-cyclohexa-2,5-diene-1,4-diylidenebis(4,7-di-tert-butyl-1,3benzodithiole-5,6-dione)) inducing the reversible coordination of water molecule to the Dy'II ion. Magnetic susceptibility measurements and ab-initio CASSCF/SI-SO calculations, confirmed by Cantilever Torque Magnetometry measurements, demonstrated that $\mathbf{D y}_{2} \mathrm{H}_{2} \mathrm{SQ}$ is a Single-Molecule Magnet with a magnetic relaxation 7000 times slower than $\mathbf{D y}_{2} \mathbf{Q}$ (at $3 \mathrm{~K}$ ) allowing a "ON-OFF" switching of the magnetic bistability.

\section{Introduction}

For the last three decades, Single-Molecule Magnets (SMMs), i.e. molecules that display slow magnetic relaxation, have been playing a key role in the field of molecular magnetism. ${ }^{1}$ Indeed, such molecular objects have potential applications in highdensity data storage, ${ }^{2}$ quantum computing, ${ }^{3}$ and spintronics. ${ }^{4}$ Even more challenging than the sole observation of the SMM behavior in high temperature range, ${ }^{5}$ is a reversible control of the magnetic properties of SMMs, which could open promising additional applications such as switches and sensors. ${ }^{6}$ So far, such tuning of physical properties in SMMs has been achieved via crystal-to-crystal chemical transformations, ${ }^{7}$ solvatoswitching, ${ }^{8}$ isomerization-switching, ${ }^{9}$ or redox-switching. ${ }^{10}$ The latter implies, most of the time, the use of redox active ligands leading to the design of multi-properties SMMs.

Focusing on the redox-switching, the use of multi-electro-active bridging ligands such as acceptor-donor-acceptor (A-D-A) triads is of particular interest because they cobble the route of magnetic modulation of the bridged magnetic active units through reduction of $A$ or oxidation of $D .{ }^{11}$ In this context, some of us already demonstrated that SMMs can be designed using redox active tetrathiafulvalene (TTF)-based ligands in its neutral and oxidized forms. ${ }^{12}$ In 2012, the synthesis and characterization of the $\left[\mathrm{Dy}_{2}(\mathrm{hfac})_{6}\left(\mathrm{H}_{2} \mathrm{O}\right)_{2}(\mathrm{~L})\right] \mathrm{SMM}$ was reported, in which the two $\mathrm{Dy}(\mathrm{hfac})_{3}$ magnetic units are bridged by the 4,4',7,7'-tetra-tert-butyl-2,2'-bi-1,3-benzo-dithiole$5,5^{\prime}, 6,6^{\prime}$-tetrone triad (L) involving both redox-active $o$-quinone (playing the role of $A$ ) and TTF moieties (playing the role of D). ${ }^{13}$ We wish now to go one step forward by designing new A-D-A triads with more powerful donor such as $p$-phenylene-extended TTF, i.e. the 2,2'-benzene-1,4-diylbis(6-hydroxy-4,7-di-tertbutyl-1,3-benzodithiol-2-ylium-5-olate ligand $\left(\mathrm{H}_{2} \mathrm{SQ}\right) .{ }^{14}$ Such chemical modifications stabilize the doubly reduced deprotonated form of the ligand opening the possibility to play with its redox activity to modulate the magnetic properties of the corresponding complexes.

Herein we present details of the redox- and hence hydroswitching of the magnetic properties between the $\left[\mathrm{Dy}{ }_{2}(\mathrm{hfac})_{6}\left(\mathrm{H}_{2} \mathrm{SQ}\right)\right] \cdot \mathrm{CH}_{2} \mathrm{Cl}_{2}\left(\mathrm{Dy}_{2} \mathrm{H}_{2} \mathrm{SQ}\right)$ and $\left[\mathrm{Dy}_{2}(\mathrm{hfac})_{6}\left(\mathrm{H}_{2} \mathrm{O}\right)_{2}(\mathbf{Q})\right.$ ] (Dy $\left.{ }_{2} \mathbf{Q}\right) \quad$ (where $\mathbf{Q}=2,2$ '-cyclohexa-2,5-diene-1,4diylidenebis(4,7-di-tert-butyl-1,3-benzodithiole-5,6-dione). The redox-activity of the triads imposes the dehydration and rehydration of the Dy'll coordination sphere, which, in turn, modifies the magnetic anisotropy and thus the slow magnetic relaxation. The compounds were characterized by X-ray crystallography, SQUID magnetometry, Cantilever Torque Magnetometry (CTM) and ab initio CASSCF/SI-SO calculations.

\section{Results and Discussion}

Synthesis and X-ray diffraction analysis.

Compound $\mathrm{Dy}_{2} \mathrm{H}_{2} \mathrm{SQ}$ was prepared by reacting Dy(hfac) $)_{3} \cdot 2 \mathrm{H}_{2} \mathrm{O}$ with purple $\mathbf{H}_{2} \mathrm{SQ}$ in $\mathrm{CH}_{2} \mathrm{Cl}_{2}$ in aerobic conditions at room temperature. Blue single crystals of $\mathrm{Dy}_{\mathbf{2}} \mathrm{H}_{\mathbf{2}} \mathrm{SQ}$ were obtained by 


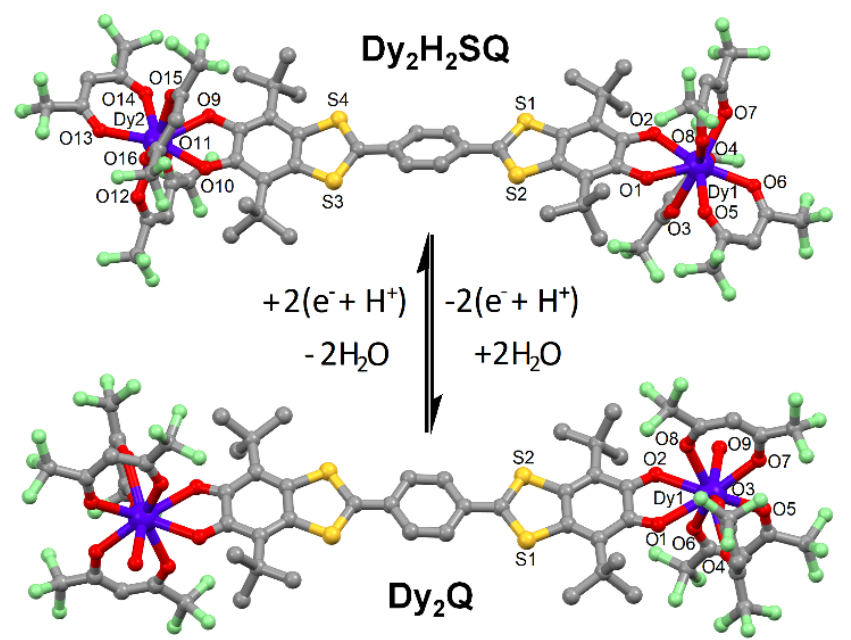

Fig. 1. Crystal structures of the dinuclear complexes $\mathrm{Dy}_{2} \mathrm{H}_{2} \mathrm{SQ}$ (top) and $\mathrm{Dy} \mathbf{y}_{2} \mathrm{Q}$ (bottom) connected by a redox and dehydration/rehydration reversible process.

layering $n$-hexane on the $\mathrm{Dy}_{2} \mathbf{H}_{\mathbf{2}} \mathrm{SQ}$ mother solution (Scheme 1) (See experimental part for Method A). It is worth noticing that $\mathrm{Dy}_{2} \mathrm{H}_{2} \mathrm{SQ}$ can be obtained also by reduction of $\mathrm{Dy}_{2} \mathrm{Q}$ with $\mathrm{Zn}^{0}$ powder at $60{ }^{\circ} \mathrm{C}$ in $\mathrm{CHCl}_{3}$ or $\mathrm{Mn}^{0}$ powder at room temperature in $\mathrm{CH}_{2} \mathrm{Cl}_{2}$ (Scheme 1) (See experimental part for Method B). Single-crystal diffraction (Table S1) revealed the formation of a dinuclear complex (Top of Fig. 1 and Fig. S1). Both Dy"l' ions are linked to three hfac anions and to the doubly reduced diprotonated form of the triad, forming an $\mathrm{O}_{8}$ coordination sphere with a $D_{2 d}$ triangular dodecahedron symmetry (SHAPE analysis, ${ }^{15}$ Table $\mathrm{S} 2$ ). The average $\mathrm{Dy}^{-} \mathrm{O}^{-}$so and $\mathrm{Dy}-\mathrm{OH}_{\text {sa }}$ distances are respectively shorter $(2.228(3) \AA)$ and longer $(2.444(4) \AA)$ than the Dy- $\mathrm{O}_{\text {hfac }}$ bond length $(2.357(4) \AA)$ giving a first indication of the bis monoprotonated form of the triad in $\mathrm{Dy}_{2} \mathrm{H}_{2} \mathrm{SQ}$. Such form is also supported by the longer bond length of C-O1/9 (1.377(6) Å) compared to C=02/10 (1.298(6) Å). An intramolecular electron transfer can take place between the two protonated semiquinone structure $\left(\mathrm{H}_{2} \mathrm{SQa}\right)$ and the chargeseparated structure $\left(\mathrm{H}_{2} \mathrm{SQ}\right.$ ) (Scheme $\mathrm{S} 1$ ). The 1,3-dithiole rings in $\mathrm{Dy}_{2} \mathrm{H}_{2} \mathrm{SQ}$ is essentially aromatic since the S1-C15 (1.679(5) $\AA$ ), S2-C15 (1.670(5) Å), S3-C22 (1.677(5) Å) and S4-C22 (1.668(5) Å) are comparable with those for TTF dications (1.670-1.690 ̊̊) while they are longer in neutral TTF (1.730-1.760 ̊). ${ }^{16-18}$ The dicationic character of the extended TTF induced a single character of the C15-C16 (1.459(6) Å) and C21-C22 (1.466(6) Å) bonds and thus allows a torsion angle of $23.4(1)^{\circ}$ between the 6-hydroxy-4,7-di-tert-butyl-1,3-benzodithiol and $p$-phenylene moieties. ${ }^{13}$ On balance, the $\mathrm{X}$-ray structure is in favor of the charge-separated structure. The crystal packing revealed the formation of layers parallel to the [110] plane and stacked together along the c axis (Fig. S2), while the dichloromethane molecules are localized between the layers. The shortest intraand inter-molecular Dy-Dy distances are equal to $21.580 \AA$ and $9.962 \AA$, respectively.

The oxidized form, $\mathrm{Dy}_{2} \mathbf{Q}$, could also be obtained by two methods. The first one consisted in the oxidation of $\mathbf{H}_{2} \mathrm{SQ}$ with an excess of $\mathrm{MnO}_{2}$ in $\mathrm{CH}_{2} \mathrm{Cl}_{2}$ at room temperature giving a deep green solution of $\mathbf{Q}$. Then $\mathbf{Q}$ was in situ reacted with Dy $(\text { hfac) })_{3} \cdot 2 \mathrm{H}_{2} \mathrm{O}$ in $\mathrm{CH}_{2} \mathrm{Cl}_{2}$ and crystallized by layering $n$-hexane, leading to the formation of dark pink single crystals of $\mathbf{D y}_{2} \mathbf{Q}$ (Scheme 1) (see Experimental part for Method A). The second method consisted in the direct oxidation of $\mathrm{Dy}_{2} \mathrm{H}_{2} \mathrm{SQ}$ in the same conditions (Scheme 1) (See Experimental part for Method B). X-ray diffraction studies (Table S1) of $\mathbf{D y}_{2} \mathbf{Q}$ indicated the formation of a dinuclear complex in which the two Dy'll ions are coordinated by three hfac- anions, one water molecule and the $o$-quinone moiety (bottom of Fig. 1 and Fig. S3). The trapped quinone form of the bridging ligand in $\mathbf{D y}_{\mathbf{2}} \mathbf{Q}$ is remarkable since it was previously established that such a form cannot be isolated in solid-state due to its instability. ${ }^{14}$ In other words, the stability of $\mathbf{Q}$ is enhanced after complexation with the $\mathrm{Dy}(\mathrm{hfac})_{3}$ units.<smiles></smiles>

$\mathrm{CH}_{2} \mathrm{Cl}_{2} / n$-hexane 2 eq Dy $(\text { hfac })_{3}\left(\mathrm{H}_{2} \mathrm{O}\right)_{2}$

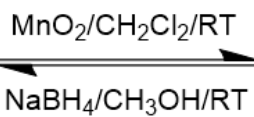<smiles>C=c1sc2c(C(C)(C)C)c3sc(=O)c=3sc1c2C(C)(C)C</smiles><smiles></smiles>

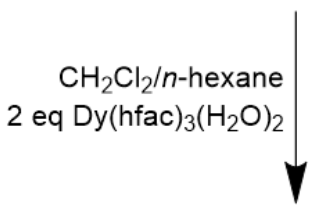

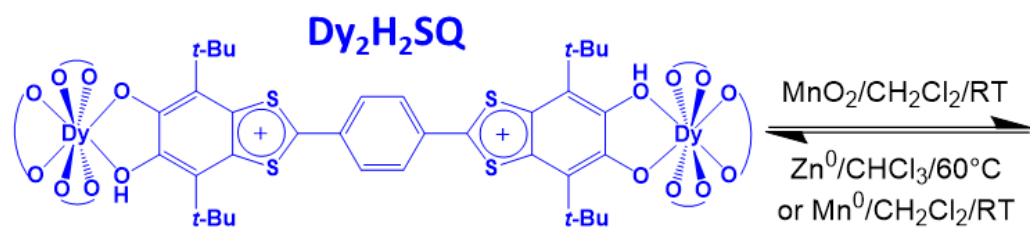

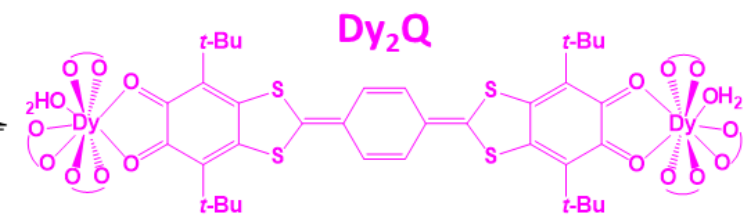

Scheme 1. Synthetic Routes for obtaining the $\mathrm{H}_{2} \mathrm{SQ}$ and Q ligands as well as the $D y_{2} \mathrm{H}_{2} \mathrm{SQ}$ and $D y_{2} \mathrm{Q}$ dinuclear complexes. 
The resulting $\mathrm{O}_{9}$ surrounding the Dy'll ion adopts a $\mathrm{C}_{4 \mathrm{v}}$ spherical capped square antiprism symmetry (Table S2). It is worth noticing that such an environment was also obtained with the $\mathbf{L}$ triad. ${ }^{13}$ In $\mathbf{D y}_{2} \mathbf{Q}$, the average Dy- $\mathrm{O}_{\mathrm{O}}, \mathrm{Dy}-\mathrm{O}_{\mathrm{w}}$ (where w indicates water) and $\mathrm{Dy}-\mathrm{O}_{\mathrm{hfac}}$ distances are respectively 2.437(10) $\AA, 2.402(10) \AA$ and 2.377(13) $\AA$, while the $\mathrm{C}=01 / 2$ distances $(1.227(18) \AA$ ) are in agreement with the quinone form. Quinone-like bond-lengths distribution in the 6membered ring and the conformation of the ligand, which is now almost planar (torsion angle of $4.8(3)^{\circ}$ ), highlight the $p$ quinodimethane form of the central ring of the ligand $\mathbf{Q}$.

The shortest Dy-Dy intramolecular distance is measured equal to $21.656 \AA$. Interestingly, the crystal packing shows the formation of a one-dimensional polymer thanks to hydrogen bonds between the coordinated water molecules and two hfacanions of the neighboring complex (09...05 $=2.883 \AA$ and $09 \cdots \mathrm{O} 2=2.868 \AA$ ) (Fig. S4) leading to much shorter Dy-Dy intermolecular distances in $\mathbf{D y}_{\mathbf{2}} \mathbf{Q}\left(6.071 \AA\right.$ ) than in $\mathbf{D y}_{\mathbf{2}} \mathbf{H}_{\mathbf{2}} \mathbf{S Q}$ (9.962 $\AA$ ). Such hydrogen bonds strongly help the crystallization of $\mathbf{D y}_{2} \mathbf{Q}$ highlighting the importance of performing the chemical oxidation in non-anhydrous conditions. The neighboring chains are almost perpendicular, in contrast to the parallel arrangement previously observed in the dinuclear compound with L. ${ }^{12}$

\section{Cyclic Voltammetry Analysis}

The redox-activity was studied by measuring the cyclic voltammogram of $\mathrm{Dy}_{2} \mathrm{H}_{2} \mathrm{SQ}$ (Fig. S5). In the cathodic region, two close reduction processes, at -0.20 and $-0.40 \mathrm{~V}$, are observed and attributed to the successive reduction of the protonated semiquinone. A third reduction is also observed at $-0.76 \mathrm{~V}$, corresponding to the reduction of the central $p$-quinonoid spacer of the extended TTF. ${ }^{14}$ In the anodic region, two oxidation peaks are observed at +1.03 and $+1.26 \mathrm{~V}$, and they can be attributed to the oxidation of the protonated semiquinone. A comparison with the free $\mathbf{H}_{\mathbf{2}} \mathbf{S Q}$ ligand shows that the coordination of the two electronic withdrawing $\mathrm{Dy}(\mathrm{hfac})_{3}$ moieties provoked a shift of $+0.23,+0.17$ and $+0.15 \mathrm{~V}$ for the reduction potentials of the two protonated semiquinone and $p$ quinonoid moieties and a shift of $+0.15 \mathrm{~V}$ for the oxidation potentials of the protonated semiquinone. This makes the reduction and the oxidation of the protonated semiquinone respectively easier and harder. ${ }^{14}$ Finally, it is worth remarking that the irreversible oxidation processes of the extended TTF into radical cation and dication species were observed at higher potentials for the free ligand.

Static Magnetic Measurements Analysis.
The static DC magnetic susceptibilities of $\mathrm{Dy}_{2} \mathrm{H}_{\mathbf{2}} \mathrm{SQ}$ and $\mathrm{Dy}_{\mathbf{2}} \mathbf{Q}$ were measured from $300 \mathrm{~K}$ to $2 \mathrm{~K}$ (Fig. 2). At room temperature, both molecules display a $\chi_{M} T$ product (with $\chi_{M}$ being the molecular magnetic susceptibility and $\mathrm{T}$ the temperature in Kelvin) consistent with two-isolated Dy'll' ions ( $J=15 / 2$ and $\mathrm{g}_{\mathrm{J}}=4 / 3$ ) systems. Values of $27.7 \mathrm{~cm}^{3} \mathrm{~K} \mathrm{~mol}^{-1}$ and $28.4 \mathrm{~cm}^{3} \mathrm{~K} \mathrm{~mol}^{-}$ 1 are found for $\mathrm{Dy}_{2} \mathrm{H}_{2} \mathrm{SQ}$ and $\mathrm{Dy}_{2} \mathbf{Q}$, respectively. The monotonical decrease of the $\chi_{M} T$ vs $T$ curve upon cooling is mainly attributed to thermal depopulation of the excited $m_{J}$ states, while dipolar interactions, mainly of intermolecular

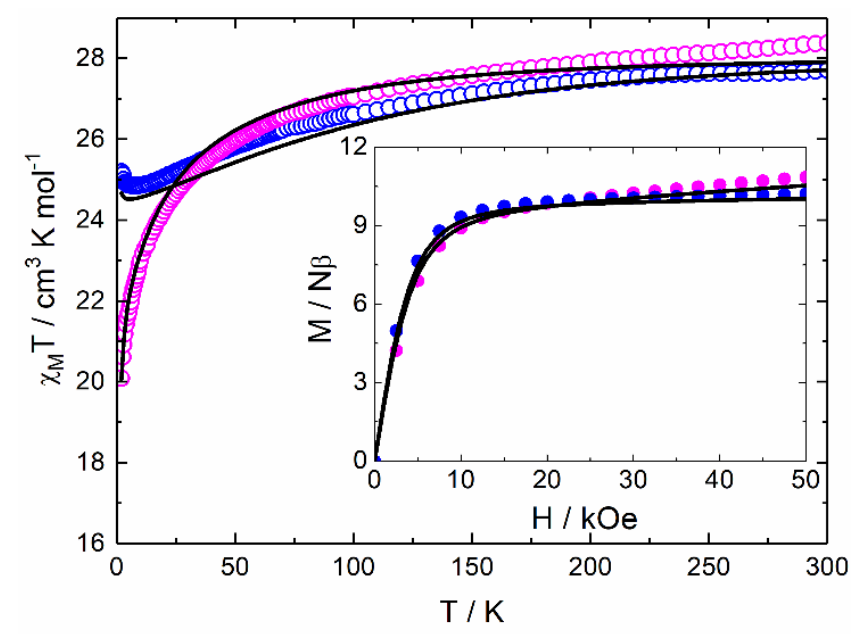

Fig. 2. Temperature dependence of $\chi_{M} T$ for $D y_{2} H_{2} S Q$ (open blue circles) and $D y_{2} Q$ (open pink circles). The inset shows the field variations of the magnetization at $2 \mathrm{~K}$. The full black lines correspond to the simulated curves from ab initio calculations.

character, could be responsible for their different behavior at low temperature. Then, $\chi_{M} T$ vs $\mathrm{T}$ curve for $\mathrm{Dy}_{2} \mathrm{H}_{2} \mathrm{SQ}$ decreases monotonically to reach $24.8 \mathrm{~cm}^{3} \mathrm{~K} \mathrm{~mol}^{-1}$ at $6 \mathrm{~K}$ and ferromagnetic interactions may be responsible for the slight increase to $25.2 \mathrm{~cm}^{3} \mathrm{~K} \mathrm{~mol}^{-1}$ at $2 \mathrm{~K}$. On the contrary, for $\mathbf{D y _ { 2 }} \mathbf{Q}$, the $\chi_{M} T$ vs $T$ curve decreases monotonically to reach $20.1 \mathrm{~cm}^{3} \mathrm{~K}$ $\mathrm{mol}^{-1}$ at $2 \mathrm{~K}$, indicating that antiferromagnetic interactions are dominating. At $2 \mathrm{~K}$, the $\mathrm{M}$ vs $\mathrm{H}$ curve (with $\mathrm{H}$ the applied magnetic field) saturates at $10.2 \mathrm{~N} \beta$ for $\mathrm{Dy}_{2} \mathrm{H}_{2} \mathrm{SQ}$, which agrees with two pure Ising $m_{J}= \pm 15 / 2$ ground states for the Dy'll ions. For $\mathbf{D y}_{2} \mathbf{Q}$ the magnetization does not saturate at $50 \mathrm{kOe}$, highlighting a lack of anisotropy on the Dy"l' ions (inset of Fig. 2).

\section{Dynamic Magnetic Measurements Analysis.}

Frequency dependent out-of-phase component of the ac susceptibility, $\chi_{M}{ }^{\prime \prime}$, was observed for $\mathrm{Dy}_{2} \mathrm{H}_{2} \mathrm{SQ}$ between 2 and $22 \mathrm{~K}$ in a zero external magnetic field (Figs. 3a and S6). At $2 \mathrm{~K}$, $\chi_{M}$ " passes through a maximum at $25 \mathrm{~Hz}$. The relaxation time $\tau$ was extracted at each temperature using an extended Debye 
model (details in SI, Table S3) to fit simultaneously the frequency dependence of $\chi_{M}{ }^{\prime \prime}$ and of the in-phase susceptibility $\chi_{M}^{\prime}$ (Fig. S7).

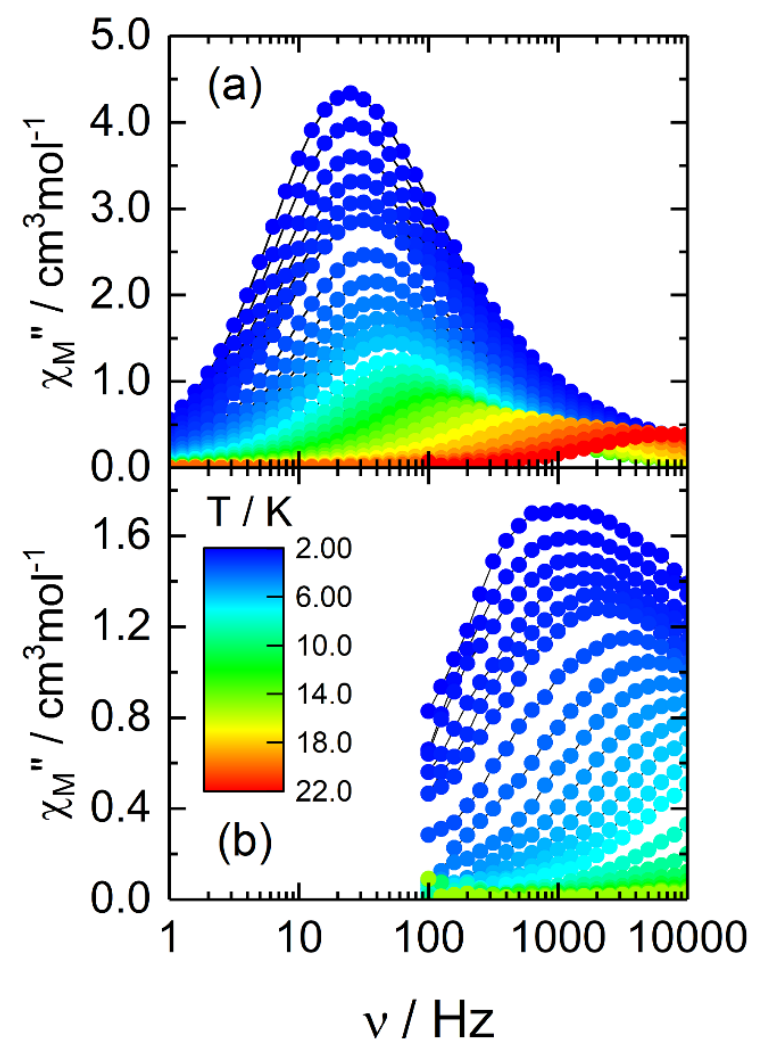

Fig. 3. Out-of-phase component of the $A C$ magnetic susceptibility data for $D_{2} \mathrm{H}_{2} \mathrm{SQ}$ (a) and $D_{y_{2}} \mathbf{Q}(\mathrm{b})$ in zero-magnetic field between 2 and $22 \mathrm{~K}$.

The normalized Cole-Cole plots in the temperature range 2 to $22 \mathrm{~K}$ are represented in Fig. 58 . The resulting plots adopt a parabolic shape giving a narrow distribution of the relaxation times $(0.09<\alpha<0.25)$. The relaxation time follows a combination of thermally dependent and thermally independent processes (Fig. 4). However, at low temperatures, the slight increase of $\tau$ can be due to the presence of small but sizeable interactions. Magnetic interactions, such as exchange/dipolar ${ }^{19}$ or hyperfine ${ }^{20}$ effects, are known to modulate the thermally independent magnetic relaxations like Quantum Tunneling of the Magnetization, QTM, without affecting the thermally activated processes such as Orbach and Raman. ${ }^{21}$ All attempts to synthesize diluted samples to cancel the dipolar interactions have been unsuccessful. A scan field of $\chi_{M}{ }^{\prime \prime}$ and $\chi_{M}{ }^{\prime} v s . v$ (Fig. S9) was performed at $2 \mathrm{~K}$ in order to suppress the QTM at low temperature. ${ }^{12 a, 22}$ Under the applied DC magnetic field of 1200 Oe value at which the slowest relaxation is observed (Figs. 5a and S10), the distribution of the relaxation time parameters $\alpha$ ranges from 0.07 to 0.34 (Fig. S11 and Table S4). Furthermore, such a field cancels the effect of weak interactions. Owing to the fact that the thermally dependent Orbach and Raman regimes are field independent, ${ }^{23}$ the parameters for these processes for $\mathrm{Dy}_{2} \mathrm{H}_{2} \mathrm{SQ}$ were kept constant going from $\mathrm{H}=0$ to $\mathrm{H}=1200$ Oe. They were evaluated by fitting simultaneously the in-field and zero-field Arrhenius plots.

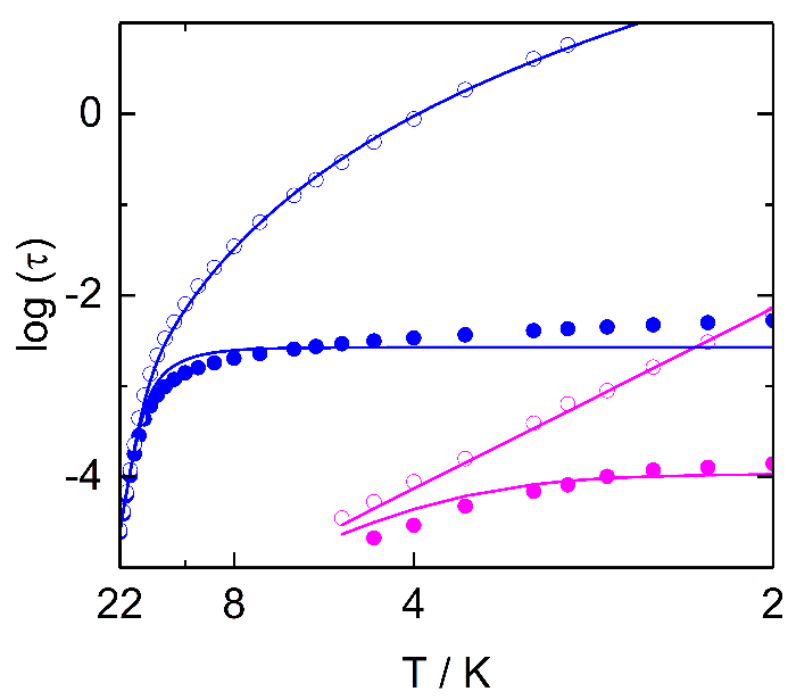

Fig. 4. Arrhenius plots of the relaxation times in zero magnetic field for $\mathrm{Dy}_{2} \mathrm{H}_{2} \mathrm{SQ}$ (blue disks) and $D y_{2} Q$ (pink disks), and in a 1200 Oe applied magnetic field for $D y_{2} \mathrm{H}_{2} \mathrm{SQ}$ (open blue circles) and $\mathbf{D y}_{2} \mathbf{Q}$ (open pink circles). Full lines are the best-fitted curves (see text).

The best fits were obtained considering both thermally dependent Orbach (green line, Fig. S12) and Raman (red line, Fig. S12) processes (equation 1)

$$
\tau^{-1}=\underbrace{C T^{n}}_{\text {Raman }}+\underbrace{\tau_{0}^{-1} \exp \left(-\frac{\Delta}{K T}\right)}_{\text {Orbach }}+\underbrace{\tau_{T I}^{-1}}_{\text {QTM }} \text { Eq. } 1
$$

with $\Delta=236(47) \mathrm{K}, \tau_{0}=5.7(51) \times 10^{-10} \mathrm{~s}$ and $C=1.3(2) \times 10^{-3} \mathrm{~s}^{-1} \mathrm{~K}$ $\mathrm{n}, \mathrm{n}=4.85$ (10) for both $\mathrm{H}=0$ Oe and $\mathrm{H}=1200$ Oe magnetic fields between 2 and $22 \mathrm{~K}$. The expected $\mathrm{n}$ value for Kramers ions should be $9,{ }^{24}$ but the presence of both acoustic and optical phonons could lead to lower values comprised between 2 and $7 .{ }^{25}$ An additional thermally independent QTM process (blue line, Fig. S12) (Equation 1) was added in absence of applied magnetic field with $\tau_{\mathrm{Tl}}=2.7(2) \times 10^{-10} \mathrm{~s} .{ }^{26}$ Passing to $\mathrm{Dy}_{2} \mathrm{Q}$, at zero external DC magnetic field, the $\chi_{M}$ " vs. $v$ curve has a maximum close to $800 \mathrm{~Hz}$ at $2 \mathrm{~K}$ (Fig. S13), which is much faster than the value found for $\mathrm{Dy}_{2} \mathrm{H}_{2} \mathrm{SQ}$ ( $25 \mathrm{~Hz}$, vide supra). The application of a 1200 Oe DC field quenches the QTM (Fig. S14) and thus shifts the maxima to lower frequencies (Fig. S15). The two $\log (\tau)$ vs T curves were obtained by manual selection of the frequency maxima due to the broad shape of the out-of-phase signal of the susceptibility. The resulting Arrhenius plots were fitted using the same method previously adopted for $D y_{2} \mathrm{H}_{2} \mathrm{SQ}$, i.e. simultaneous fitting the two Arrhenius plots obtained in- zero and in-field. The best fit for $\mathrm{H}=\mathrm{O}$ Oe was obtained combining the thermally activated Orbach process for the high temperatures (green line, Fig. S16) with the temperature independent QTM (blue line, Fig. S16) process between 2 and $4.5 \mathrm{~K}$ (Fig. 4). The parameters extracted by the fit are $\Delta=18.3$ (8) $\mathrm{K}, \tau_{0}=7.6(2) \times 10^{-7} \mathrm{~s}$ and $\tau_{T I}=1.1(1) \times 10^{-4} \mathrm{~s}$. When a $1200 \mathrm{Oe}$ static field is applied, the Arrhenius plot is fitted by considering a pure Orbach process and with the same parameters previously obtained. Thus, one could note that $\mathrm{Dy}_{2} \mathrm{H}_{2} \mathrm{SQ}$ relaxes 7000 times slower than $\mathbf{D y}_{2} \mathbf{Q}$ at $3 \mathrm{~K}$ and under $1200 \mathrm{Oe}$. The hysteresis loops recorded at sub-kelvin temperatures highlight this difference. The loop is closed at any field at $0.5 \mathrm{~K}$ for $\mathrm{Dy}_{2} \mathrm{Q}$, whereas it is open with a butterfly shape for $\mathrm{Dy}_{2} \mathrm{H}_{2} \mathrm{SQ}$ (Fig. 6). 
Such behaviors are directly related to the different magnetic anisotropy of the Dy"II ion induced by the a $\mathrm{D}_{2 d} \mathrm{O}_{8}\left(\mathrm{Dy}_{2} \mathrm{H}_{2} \mathrm{SQ}\right)$ and $\mathrm{C}_{4 v} \mathrm{O}_{9}\left(\mathrm{Dy}_{2} \mathrm{Q}\right)$ coordination environments, as well as by the different electronic distribution on surrounding ligands. This hypothesis is confirmed by $a b$ initio calculations and single crystal magnetic investigations discussed in the following sections.

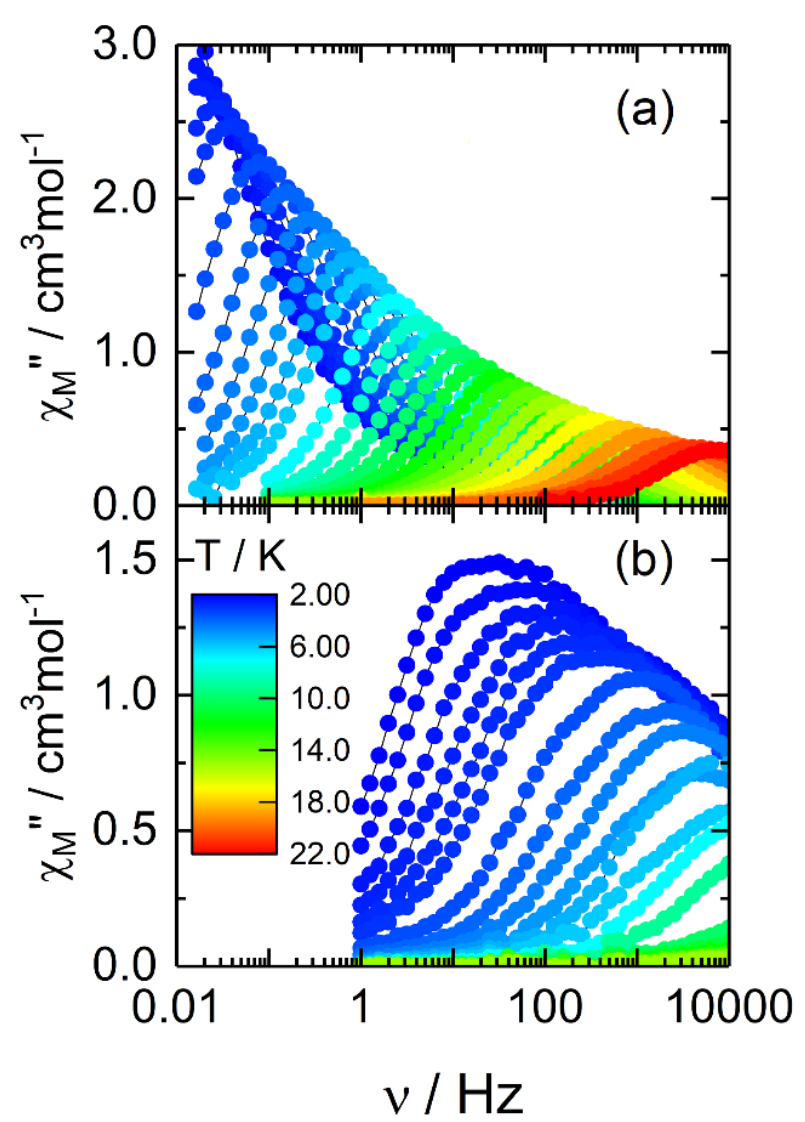

Fig. 5. Out-of-phase component of the $A C$ magnetic susceptibility data for $\mathrm{Dy}_{2} \mathrm{H}_{2} \mathrm{SQ}$ (a) and $\operatorname{Dy}_{2} Q(b)$ in a 1200 Oe applied field

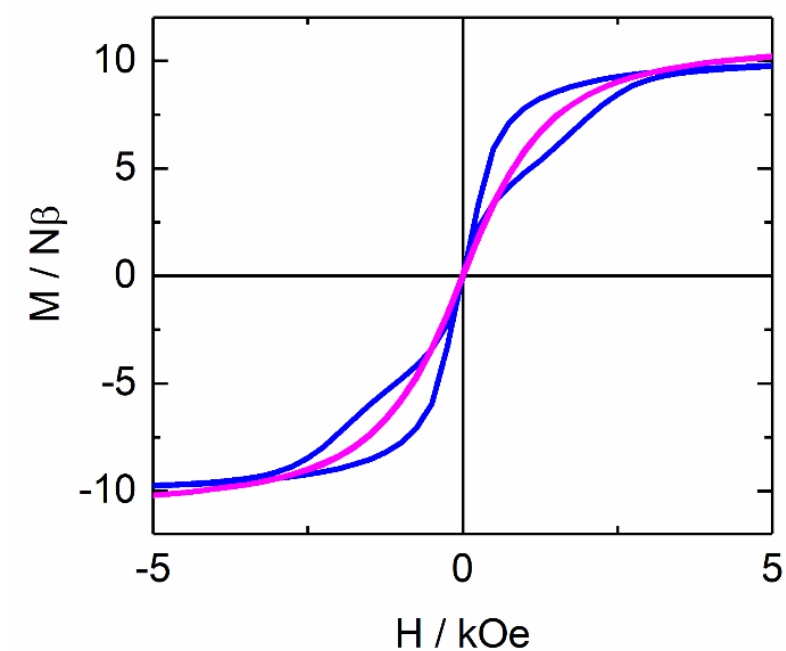

Fig. 6. Magnetic hysteresis loops at $0.5 \mathrm{~K}$ with a sweep rate of $16 \mathrm{Oe} \mathrm{s}^{-1}$ for $\mathrm{Dy}_{2} \mathrm{H}_{2} \mathrm{SQ}$ (blue line) and $\mathrm{Dy}_{2} \mathrm{Q}$ (pink line).
Theoretical Calculations and Cantilever Torque Magnetometry Measurements.

In order to propose a quantitative interpretation of the magnetic data, CASSCF/SI-SO ab initio calculations were performed on each asymmetric Dy'll center of complexes $\mathrm{Dy}_{2} \mathrm{H}_{2} \mathrm{SQ}$ and $\mathrm{Dy}_{2} \mathrm{Q}$, leading to the following models: [Dy1HSQ] , [Dy2HSQ] and DyQ (Fig. 7; computational details in Experimental part). Ab initio calculations on [Dy1HSQ] and [Dy2HSQ] show very similar single-ion properties, with an almost Ising character of the ground state doublet (GD) magnetic anisotropy (Dy1: $g_{x}=0.00, g_{y}=0.00$ and $g_{z}=19.69$; Dy2: $g_{x}=0.00, g_{y}=0.00$ and $g_{z}=19.70 ;$ Tables S5-S6). The ground state doublet is mainly composed of $m_{\jmath}= \pm 15 / 2$ (97\%).
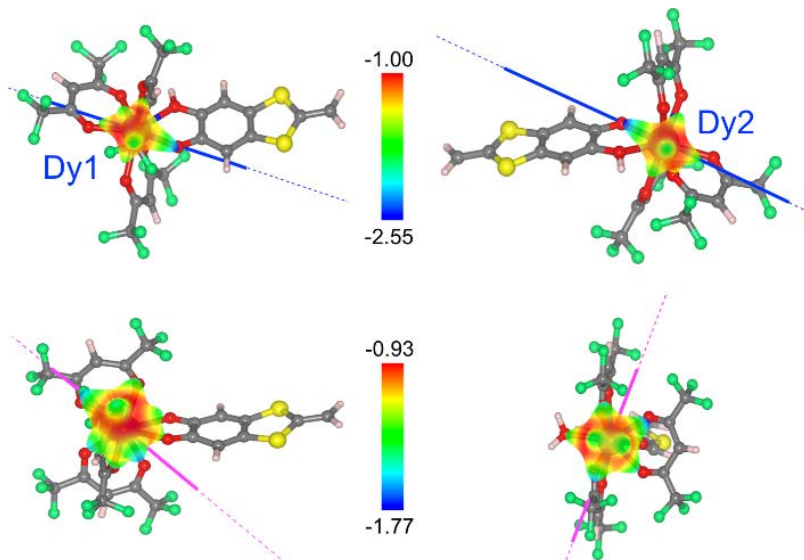

Fig. 7. Representation of the local ground state magnetic anisotropy axes and molecular electrostatic potential for [Dy1HSQ] and [Dy2HSQ] (top) and for DyQ (bottom, views from the side and along the ligand).

For both Dy"ll centers, the orientation of the main anisotropy axes is calculated along the deprotonated $\mathrm{O} 2$ and $\mathrm{O} 10$ atoms (Fig. 7). The analysis of the molecular electrostatic potential, using our home-made code CAMMEL (description in the Experimental part), reveals that this orientation corresponds to the most-negatively charged potential. ${ }^{27-29}$ From this electrostatic distribution one may notice the strong anisotropy of the total molecular electrostatic potential along the nonprotonated semiquinonate $\mathrm{O}$ atom of the extended-TTF ligand, which shows the shortest Dy-O distance of $2.23 \AA$, while the second $\mathrm{O}$ atom lies at $2.44 \AA$ from the metal.

In order to validate results of the $a b$ initio calculations, angular resolved magnetic measurements on a single crystal of $\mathrm{Dy}_{2} \mathrm{H}_{2} \mathrm{SQ}$ were performed using Cantilever Torque Magnetometry (CTM). Indeed, such a technique allows the experimental determination of both the magnitude and orientation of the magnetic anisotropy. ${ }^{30}$ In general, the single crystal is mounted on the cantilever, acting as a capacitor plate. The cantilever can be rotated inside the DC applied magnetic field and $\theta$ defines the rotation angle, i.e. the angle between the cantilever plane and the direction of the magnetic field. The measured physical quantity is the change in capacitance due to the deflection of the cantilever's plate produced by the 
magnetic torque of the sample. This measured quantity is indeed proportional to the magnetization torque, $\tau_{\text {Mag }}$ along the rotation axis, which corresponds to the vector product between the magnetization $\mathbf{M}$ and the applied magnetic field $\mathbf{H}$.

In the low-field limit $g \mu_{B} J H<<k_{B} T$ the resulting curve has a sinusoidal behavior:

$\tau_{\mathrm{Y}}=M_{Z} H_{X}-M_{X} H_{Z}=H^{2}\left(\chi_{Z Z}-\chi_{X X}\right) \sin \eta \cos \eta$

Eq. 2

where $\mathrm{XYZ}$ is the laboratory reference frame with the rotation performed around the $Y$-axis, while $\chi$ is the susceptibility tensor and $\eta$ the angle between the projection of the molecular anisotropy principal axis in the $\mathrm{XZ}$ plane and the direction of the applied magnetic field $\mathbf{H}$.

According to Eq. 2, each time one of the principal anisotropy magnetic axes of the molecule, or its projection in the scanned plane, is parallel to the magnetic field vector, then $\tau_{\text {Mag }}$ is zero. In the high magnetic field regime, i.e., $g \mu_{B} J \mathrm{H}>>\mathrm{k}_{B} T$ the torque changes more steeply when the magnetic field is close to the hard direction of the magnetic anisotropy. This effect enables us to disentangle the non-collinear contributions, such as those provided by different magnetic centers in the molecule. ${ }^{31}$ The orientation of the anisotropy can be solved probing two different crystallographic planes.

The measurements were performed on a single crystal of $\mathrm{Dy}_{2} \mathrm{H}_{2} \mathrm{SQ}$ with dimensions $0.5 \times 0.5 \times 0.1 \mathrm{~mm}$. The crystal was mounted on an acetate foil, which in turn was placed on the cantilever plate (see Fig. S17 for details on the orientation). In Rotation 1 , the rotation axis $Y$ was parallel to the crystallographic axis $c^{*}$, thus the magnetic field scanned the $a b$ plane. Rotation 2 was instead performed along the vector normal to the $\left[\begin{array}{lll}2 & 15 & 0\end{array}\right]$ face, i.e. between the $a$ and $b$ axes. In this rotation the field was parallel to $-c^{*}$ at $\theta=0^{\circ}$. The measurements were performed at several temperatures between 2 and $50 \mathrm{~K}$ and varying the magnetic field between 3 and $12 \mathrm{~T}$ (Figs. 8 and S18-19). Fig. 8 reports the results of the measurements at $2 \mathrm{~K}$ for the two rotations and magnetic field values between 3 and $9 \mathrm{~T}$. In Rotation 1, the first zero is found at $75^{\circ}$, that corresponds to the crystallographic axis $a$ parallel to the magnetic field; looking at the asymmetric shape of the curves it is clear that the direction $a$ has an easy axis character. After $90^{\circ}$, i.e. at $165^{\circ}$, a second zero is found and it corresponds to the hard axis $b$ parallel to the magnetic field. These findings agree with the fact that $b$ is also the $C_{2}$-symmetry axis of the $\mathrm{P}_{2}$ /c space group, and it must coincide with one of the principal anisotropy axes of the crystal. Instead, in Rotation 2 no symmetry constraints are present. The first zero is at $27^{\circ}$ and it has a hard character, whereas the second is at $117^{\circ}$ with an easy character. It is worth pointing out that in this case, fits of torque magnetization are not trivial because of the significant number of parameters that over-parametrize the problem. Indeed, even in the simplest case, which corresponds to the pseudo-spin $1 / 2$ approximation, the modellization of the problem requires to find the $\psi, \xi$, and $\rho$ Euler angles that connect the crystallographic $a b c^{*}$ and molecular $x y z$ frames, in addition to the $g_{x}, g_{y}$ and $g_{z}$ values. Moreover, since the two Dy"l' centers of the $\mathrm{Dy}_{2} \mathrm{H}_{2} \mathrm{SQ}$ molecule are not equivalent, the parameters of the fits must be considered twice for a total of 12 parameters. For this reason, only simulations based on the parameters obtained by $a b$ initio calculations were performed.

The simulation of the torque magnetization for $2 \mathrm{~K}$ has been made considering both the pseudo-spin $1 / 2$ approximation (solid lines in Fig. S18) and the full Hamiltonian with all the 27 crystal field parameters (Fig. 8). In both cases, the parameters obtained from $a b$ initio calculations well-reproduce the experimental curves. Indeed, the values of $\theta$ at which $\tau_{\mathrm{Mag}}=0$ occurs are always in agreement with the experimental findings. This indicates that the principal magnetic anisotropy directions, as well as the composition of the crystal field parameters, for the two Dy"l' centers, are well-computed.

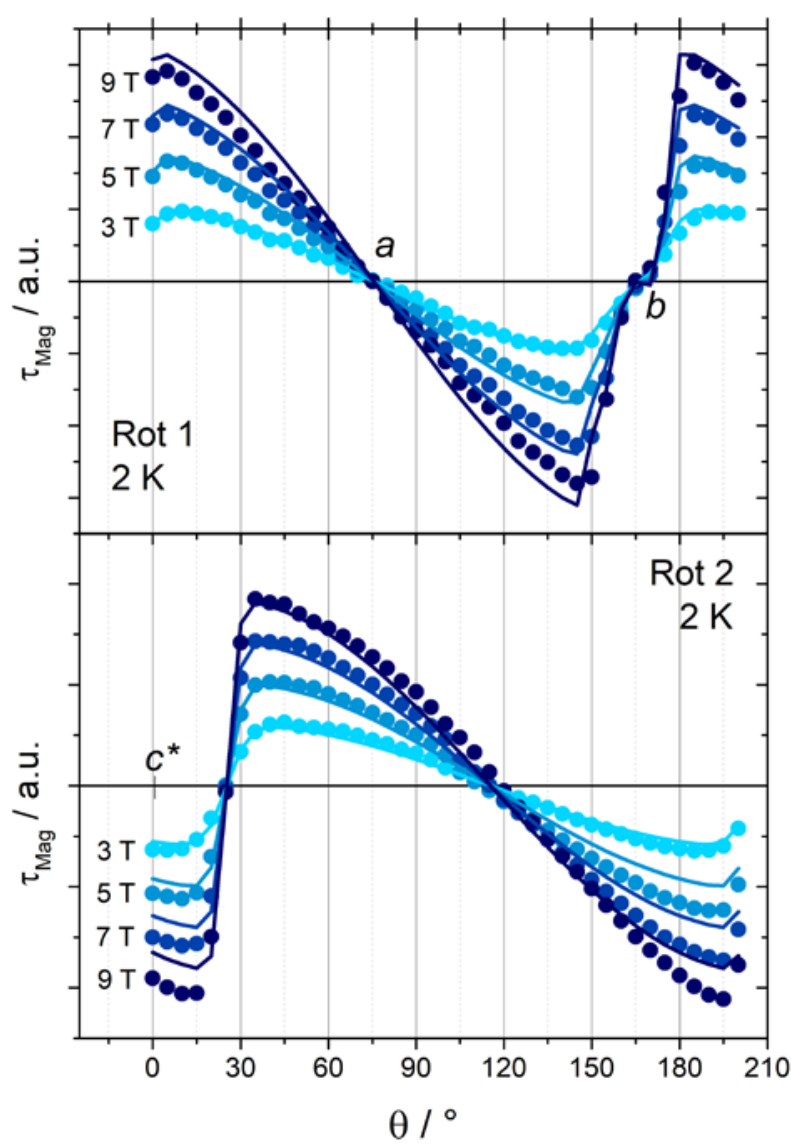

Fig. 8. Angular dependence of the magnetic torque (dots) of a single crystal of $D y_{2} \mathrm{H}_{2} \mathrm{SQ}$ measured using Cantilever Torque Magnetometry at $2 \mathrm{~K}$ and under several applied DC magnetic fields. Rotation 1 (top) and 2 (bottom) were performed following the scheme reported in Fig. S17. Simulations (solid lines) were obtained considering the full Hamiltonian parameters obtained by ab initio calculations.

It must be underlined that the simulation is even able to reproduce the small plateau observed around $165^{\circ}$, which comes out from the symmetry nature of the $b$ axis. The intensity of $\tau_{\text {Mag }}$ is also a key indicator of the quality of the simulations. It should be noted that a scale factor is applied, which takes into account the mass of the sample and other instrumental parameters, but this factor is unique for all data reported here. Remarkably, the agreement is maintained even extending the 
experiment and simulation up to $50 \mathrm{~K}$ (Fig. S19), thus evidencing the robustness and accuracy of the $a b$ initio calculations.

In the case of $\mathbf{D y}_{\mathbf{2}} \mathbf{Q}$, the calculations on the single asymmetric center reveal a much smaller splitting of the ${ }^{6} \mathrm{H}_{15 / 2}$ multiplet. The presence of low lying excited states leads to a decrease of the ground doublet (GD) magnetic anisotropy with non-zero transversal components $\left(g_{x}=0.07, g_{y}=0.08\right)$ and lower main component $\left(g_{z}=18.93\right)$. However, the composition of the GD remains mainly of $m_{\jmath}= \pm 15 / 2(89 \%)$ character (Table S7). The computed orientation of the GD magnetic axis of DyQ appears along the $\mathrm{O}$ atoms of the "axial" hfac ligands, perpendicular to the plane containing the quinone moiety (Fig. 7). Such a shift of the magnetic axis might be ascribed to the coordination of the water molecule in the coordination sphere of the Dy $y^{\prime \prime \prime}$ ion and the deprotonation of the extended-TTF ligand, leading to an increase of the Dy-O distance from $2.23 \AA$ (deprotonated) to $2.42 \AA$ (protonated). Such a modification in the coordination sphere has a direct effect on the molecular electrostatic potential which shows a more "isotropic" distribution of the potential around the metal center. This variation is also evidenced by the different components of the total molecular electrostatic potential (Figs. S20 and S21). In both systems, the decomposition of the total electrostatic potential reveals a major contribution from the quadrupolar term, a trend already observed in previous works. ${ }^{29,32}$

The computation of the single-ion anisotropy barriers of [Dy1HSQ] and [Dy2HSQ] are shown in Fig. S22.33 The calculated transition elements of the magnetic moment, between the states lying at $300 \mathrm{~cm}^{-1}$ from the GD, show a main relaxation pathway leading to an effective energy barrier equals to $280 \mathrm{~cm}^{-1}(403 \mathrm{~K})$, with the crossing at the second excited doublet. ${ }^{6}$ Such a value is far from the experimentally determined barrier height of $164 \mathrm{~cm}^{-1}(236 \mathrm{~K})$. In the case of DyQ, non-negligible QTM and TA-QTM coefficients are observed, explaining the fast relaxation behavior observed experimentally (Fig. S23).

From this "local" description (considering a single magnetic center) of the magnetic properties, one may see an excellent agreement between the experimental and calculated field dependence of the magnetization (Inset of Fig. 2). On the contrary the $\chi_{M} T$ vs. $T$ curve at low temperature is not reproduced properly (Figs. S24 and S25). Such a discrepancy between calculations and experiments is often ascribed to weak inter/intramolecular interactions between the magnetic centers in the crystal. The increase observed in the low temperature range of the $\chi_{M} T$ vs. T curve of $\mathrm{Dy}_{2} \mathrm{H}_{2} \mathrm{SQ}$ suggests predominant ferromagnetic interactions. In the case of $\mathbf{D y _ { 2 }} \mathbf{Q}$, the sharp decrease of the magnetic susceptibility is, on the contrary, indicative of dominant antiferromagnetic interactions. Due to the complexity of the bridging ligands and the large distance between the magnetic centers, the intramolecular exchange term is not considered in this study. Therefore, the different behavior can be rationalized by assuming that only dipolar interactions are active between Dy'II centers. As implemented in the POLY_ANISO software, ${ }^{34}$ in the pseudospin $\tilde{S}_{i}=1 / 2$ formalism the dipolar interaction can be modelled with the following interaction Hamiltonian:

$$
H_{\text {int }}=-\sum_{i}^{N} J_{i} \tilde{S}_{i} \tilde{S}_{j}
$$

where $J_{i}$ corresponds to the dipolar coupling constant between center $i$ and $j$ while $\tilde{S}_{i}$ denotes the effective spin of center $i$. The pairwise contributions to the total interaction Hamiltonian considered in the calculations are depicted in Fig. S26 and Fig. S27 and correspond to the sphere containing the first magnetic neighbors of $\mathrm{Dy}_{2} \mathrm{H}_{2} \mathrm{SQ}$ and $\mathrm{Dy_{2 }} \mathbf{Q}$, respectively.

In the case of $\mathrm{Dy}_{2} \mathrm{H}_{2} \mathrm{SQ}$, the two asymmetric Dy ${ }^{\text {III }}$ centers exhibit very similar magnetic environment leading to two types of intermolecular interactions, namely Dy1-Dy1 (Dy2-Dy2) and Dy1-Dy2 interactions. The latter exhibit larger $J$ values due to the shorter Dy1-Dy2 distances in the crystal (Table S8). One may notice that both weak Dy1-Dy2 intramolecular and Dy1Dy1/Dy2-Dy2 intermolecular dipolar interactions are in the same range of values. The overall description of the magnetic environment of $\mathrm{Dy}_{2} \mathrm{H}_{2} \mathrm{SQ}$ is dominated by the major ferromagnetic contributions of Dy1-Dy2 interactions leading to the increase of the $\chi_{M} T$ product at low temperatures. The computation of the DC magnetic properties including such interactions is shown in Fig. 2 and reproduces the experimental trend of the $\chi_{M} T$ curve.

A similar computational approach was then considered for $\mathrm{Dy}_{\mathbf{2}} \mathbf{Q}$, with a single type of intermolecular Dy-Dy interaction. One may see, from Fig. S25 and Table S9, that the shortest DyDy distance $(6.07 \AA)$ leads to the largest antiferromagnetic $J_{1}=-$ $0.65 \mathrm{~cm}^{-1}$ constant. All the other contributions (intramolecular and intermolecular) lies one order of magnitude below $J_{1}$, which is explained by the much larger Dy-Dy distances. The computation of this major term in the DC magnetic properties leads to a better description of the low temperature behavior (Fig. 2).

\section{Conclusions}

Starting from the dinuclear complex $\mathrm{Dy}_{2} \mathrm{H}_{2} \mathrm{SQ}$ involving the $\mathrm{H}_{2} \mathrm{SQ}$ triad, the reversible chemical oxidation of $\mathrm{H}_{2} \mathrm{SQ}$ into $\mathbf{Q}$ leads to the new dinuclear complex $\mathbf{D y}_{\mathbf{2}} \mathbf{Q}$. Both complexes are characterized by X-ray diffraction on single crystal. The reversible oxidation induces strong changes in the coordination sphere of the Dy'II ions with the addition of a water molecule. These structural and electronic evolutions are at the origin of drastic modulations of the magnetic relaxation in such way that $\mathrm{Dy}_{2} \mathrm{H}_{2} \mathrm{SQ}$ displays magnetic bistability while $\mathrm{Dy}_{\mathbf{2}} \mathbf{Q}$ does not. Cantilever Torque Magnetometry measurements confirmed the rationalization of the magnetic behavior using ab-initio CASSCF/SI-SO calculations. The change in magnetic anisotropy is also responsible of a change in the sign of the dominating intermolecular dipolar interactions. In conclusion, a simultaneous reversible redox and solvato-magnetic switching is here evidenced. Besides, the $\mathbf{H}_{2} \mathbf{S Q}$ triad can be reversibly reduced in $\mathrm{H}_{4}$ CAT (CAT: catechol) ${ }^{35,36}$ which could open the route to novel redox-switching of the SMM behavior.

\section{Experimental section}


Materials. The precursor Dy $(\mathrm{hfac})_{3} \cdot 2 \mathrm{H}_{2} \mathrm{O}\left(\mathrm{hfac}^{-}=1,1,1,5,5,5-\right.$ hexafluoroacetylacetonate anion) ${ }^{37}$ and the 2,2'-benzene-1,4diylbis(6-hydroxy-4,7-di-tert-butyl-1,3-benzodithiol-2-ylium-5olate triad $\left(\mathrm{H}_{2} \mathrm{SQ}\right)^{14}$ were synthesized following previously reported methods. All solvents were dried using standard procedures. All other reagents were purchased from Aldrich Co., Ltd. and used without further purification.

Synthesis of $\left[\mathrm{Dy}_{2}(\mathrm{hfac})_{6}\left(\mathrm{H}_{2} \mathrm{SQ}\right)\right] \cdot \mathrm{CH}_{2} \mathrm{Cl}_{2}\left(\mathrm{Dy}_{2} \mathrm{H}_{2} \mathrm{SQ}\right)$.

Method A: $65.8 \mathrm{mg}$ of $\mathrm{Dy}(\mathrm{hfac})_{3} \cdot 2 \mathrm{H}_{2} \mathrm{O}(0.08 \mathrm{mmol})$ were dissolved in $10 \mathrm{~mL}$ of $\mathrm{CH}_{2} \mathrm{Cl}_{2}$ and then added to a purple solution of $10 \mathrm{~mL}$ of $\mathrm{CH}_{2} \mathrm{Cl}_{2}$ containing $26.4 \mathrm{mg}$ of $\mathrm{H}_{2} \mathrm{SQ}$ (0.04 mmol). The purple solution of $\mathrm{H}_{2} \mathrm{SQ}$ immediately turned blue with the addition of the Dy"ll salt. After 15 minutes of stirring, $20 \mathrm{~mL}$ of $n$ hexane were layered at room temperature in the dark. Slow diffusion led to dark blue single crystals of $\mathrm{Dy}_{2} \mathrm{H}_{2} \mathrm{SQ}$ that are suitable for X-ray diffraction studies. Yield (determined from isolated single crystals) $73.3 \mathrm{mg}$ (79\%). Anal. Calcd (\%) for $\mathrm{C}_{67} \mathrm{H}_{50} \mathrm{Cl}_{2} \mathrm{Dy}_{2} \mathrm{~F}_{36} \mathrm{O}_{16} \mathrm{~S}_{4}$ : C 34.67, H 2.16; found: C 34.69, H 2.22. I.R. (KBr): 2966 (w), 2928 (w), 2878 (w), 1651 (s), 1558 (w), 1533 $(\mathrm{m}), 1507(\mathrm{~m}), 1422(\mathrm{~s}), 1412$ (s), $1388(\mathrm{~s}), 1257$ (s), 1205 (s), $1146(\mathrm{~s}), 1103(\mathrm{w}), 801(\mathrm{~m}), 662(\mathrm{~m}), 585(\mathrm{~m})$ and $468(\mathrm{~m}) \mathrm{cm}^{-1}$. Method B: $22.6 \mathrm{mg}$ of single crystals of $\mathrm{Dy}_{2} \mathbf{Q}(0.01 \mathrm{mmol})$ were dissolved in $30 \mathrm{~mL}$ of $\mathrm{CH}_{2} \mathrm{Cl}_{2}$ and $2 \mathrm{~g}$ of reducing $\mathrm{Mn}^{0}$ powder was added and then the mixture was stirred $2 \mathrm{~h}$ at room temperature under an argon atmosphere. After filtration and addition of $n$-hexane, single crystals of $D y_{2} \mathrm{H}_{2} \mathrm{SQ}$ were obtained. Yield (determined from isolated single crystals) $5.3 \mathrm{mg}(23 \%)$. When $\mathrm{Zn}^{0}$ is used as reducing agent, the $\mathrm{CH}_{2} \mathrm{Cl}_{2}$ is replaced by $\mathrm{CHCl}_{3}$ and the mixture is stirred at $60{ }^{\circ} \mathrm{C}$ instead of room temperature.

Synthesis of $\left[\mathrm{Dy}_{2}(\mathrm{hfac})_{6}\left(\mathrm{H}_{2} \mathrm{O}\right)_{2}(\mathrm{Q})\right]\left(\mathrm{Dy}_{2} \mathrm{Q}\right)$.

Method A: $13.2 \mathrm{mg}$ of $\mathbf{H}_{2} \mathrm{SQ}(0.02 \mathrm{mmol})$ were dissolved in 20 $\mathrm{mL}$ of $\mathrm{CH}_{2} \mathrm{Cl}_{2}$ and then stirred in presence of $1.5 \mathrm{~g}$ of $\mathrm{MnO}_{2}$. The starting purple solution turned green (oxidation of $\mathbf{H}_{2} \mathbf{S Q}$ into Q) and after $45 \mathrm{~min}$ of stirring it was filtered directly in a $\mathrm{CH}_{2} \mathrm{Cl}_{2}$ solution $(5 \mathrm{~mL})$ of Dy $(\mathrm{hfac})_{3} \cdot 2 \mathrm{H}_{2} \mathrm{O}(32.8 \mathrm{mg}, 0.04 \mathrm{mmol})$. The green solution turned to a dark pink color. Slow diffusion of $n$ hexane into the resulting dark pink solution led to formation of dark pink single crystals of $\mathbf{D y}_{2} \mathbf{Q}$ which were suitable for X-ray analysis. Yield (determined from isolated single crystals) 32.2 mg (71 \%). Anal. Calcd (\%) for $\mathrm{C}_{66} \mathrm{H}_{46} \mathrm{Dy}_{2} \mathrm{~F}_{36} \mathrm{O}_{18} \mathrm{~S}_{4}$ : C 34.98, H 2.03; found: C 35.09, H 2.15. I.R. (KBr): 2964 (w), 2927 (w), 2861 (w), 1654 (s), 1532 (s), 1422 (s), 1395 (m), 1363 (m), 1256 (s), 1203 (s), $1146(\mathrm{~s}), 1103(\mathrm{w}), 942(\mathrm{~m}), 915(\mathrm{~m}), 854(\mathrm{~m}), 799(\mathrm{~m}), 769$ $(\mathrm{m}), 662(\mathrm{~m}), 585(\mathrm{~m}), 548(\mathrm{~m})$ and $529(\mathrm{w}) \mathrm{cm}^{-1}$.

Method B: $\mathbf{D y}_{2} \mathbf{Q}$ can be directly obtained by oxidation of the complex $\mathrm{Dy}_{2} \mathrm{H}_{2} \mathrm{SQ}$. $22.6 \mathrm{mg}$ of $\mathrm{Dy}_{\mathbf{2}} \mathbf{Q}(0.01 \mathrm{mmol})$ were dissolved in $20 \mathrm{~mL}$ of $\mathrm{CH}_{2} \mathrm{Cl}_{2}$ and then stirred in presence of $1.5 \mathrm{~g}$ of $\mathrm{MnO}_{2}$. The starting blue solution turned dark pink (oxidation of $D y_{2} \mathrm{H}_{2} \mathrm{SQ}$ into $D y_{2} Q$ ). Slow diffusion of $n$-hexane into the resulting dark pink solution led to formation of dark pink single crystals of $\mathbf{D y}_{2} \mathbf{Q}$ which were suitable for $\mathrm{X}$-ray analysis. Yield (determined from isolated single crystals) $14.4 \mathrm{mg}$ (62\%).

Characterization. The elemental analyses of the compounds were performed at the Centre Régional de Mesures Physiques de l'Ouest, Rennes. Cyclic voltammetry was carried out in dried and degassed $\mathrm{CH}_{2} \mathrm{Cl}_{2}$ solution, containing $0.1 \mathrm{M} \mathrm{N}\left(\mathrm{C}_{4} \mathrm{H}_{9}\right)_{4} \mathrm{PF}_{6}$ as supporting electrolyte. Voltammograms were recorded at 100 $\mathrm{mVs}^{-1}$ at a platinum disk electrode. The potentials were measured versus a saturated calomel electrode (SCE).

$X$-ray diffraction study. Single crystals of $\mathrm{Dy}_{2} \mathrm{H}_{2} \mathrm{SQ}$ and $\mathrm{Dy} \mathbf{2}_{2} \mathrm{Q}$ were mounted on a APEXIII D8 VENTURE Bruker-AXS diffractometer for data collection (MoK $\alpha$ radiation source, $\lambda=$ $0.71073 \AA$ ) , from the Centre de Diffractométrie (CDIFX), Université de Rennes 1, France (Table 1). The structure was solved with a direct method using the SHELXT program ${ }^{38}$ and refined with a full matrix least-squares method on $\mathrm{F}^{2}$ using the SHELXL-14/7 program ${ }^{39}$. A SQUEEZE procedure of PLATON ${ }^{40}$ was performed as the structure for $\mathbf{D y}_{\mathbf{2}} \mathbf{Q}$ contains large solvent accessible voids in which residual peaks of diffraction were observed. Complete crystal structure results as CIF files including bond lengths, angles, and atomic coordinates are deposited as Supporting Information. They have been deposited in the Cambridge Structural Database as CCDC1830437 (Dy $\mathbf{H}_{2} \mathbf{S Q}$ ) and CCDC1830438 (Dy2 Q).

Magnetic measurements. The dc magnetic susceptibility measurements were performed on solid samples with a Quantum Design MPMS-XL SQUID magnetometer between 2 and $300 \mathrm{~K}$ in applied magnetic field of $0.02 \mathrm{~T}$ for temperatures of $2-20 \mathrm{~K}, 0.2 \mathrm{~T}$ between 20 and $80 \mathrm{~K}$ and $1 \mathrm{~T}$ for higher temperatures than $80 \mathrm{~K}$. The microcrystallites are immobilized in a pellet made with Teflon tape. The measurements were all corrected for the diamagnetic contribution as calculated with Pascal's constants. The ac magnetic susceptibility measurements were performed on a Quantum Design MPMSXL SQUID for frequencies between 0.01 and $1000 \mathrm{~Hz}$ and a Quantum Design PPMS magnetometers for frequencies between 1000 and $10000 \mathrm{~Hz}$. For the CTM measurements, a single crystal was attached to a square acetate foil with silicon vacuum grease, and its faces were indexed using a SCD Oxford Xcalibur3 X-ray diffractometer. The main part of the instrument consisted of a home-made two-legged CuBe cantilever separated by $0.1 \mathrm{~mm}$ from a gold plate. The cantilever was inserted into an Oxford Instruments MAGLAB2000 platform with automated rotation in a vertical magnet. The magnetometer can switch the magnetic field between 0 and 12 $\mathrm{T}$ and the temperature between 2 and $300 \mathrm{~K}$. The capacitance was detected with an Andeen-Hagerling 2500A Ultra Precision Capacitance Bridge.

Computational details. Quantum chemical calculations were realized on model complexes of $\mathrm{Dy}_{2} \mathrm{H}_{2} \mathrm{SQ}$ and $\mathrm{Dy}_{\mathbf{2}} \mathrm{Q}$, namely [Dy1HSQ]', [Dy2HSQ] and DyQ respectively (Fig. 7). For both models, the atomic positions were extracted from the X-ray crystal structures and the butyl moieties located on the benzene rings of the TTF have been replaced by hydrogen atoms. The optimization of the hydrogen and fluorine positions, while other atomic positions were kept frozen, have been carried out on the Y'II parent molecules by Density Functional Theory (DFT) as implemented in the Gaussian 09 (revision D.01) package ${ }^{41}$ using the PBEO hybrid functional. ${ }^{42,43}$ The "Stuttgart/Dresden » basis sets and effective core potentials were used to describe the yttrium atom ${ }^{44}$ while other atoms were described with the SVP basis sets. ${ }^{45}$ Wavefunction-based calculations were carried out on the optimized molecular structures (replacing one of the Dy $y^{\prime \prime \prime}$ 
ions by $\mathrm{Y}^{\text {III) }}$ by using the SA-CASSCF/RASSI-SO approach, as implemented in the MOLCAS quantum chemistry package (versions 8.0). ${ }^{46}$ In this approach, the relativistic effects are treated in two steps on the basis of the Douglas-Kroll Hamiltonian. First, the scalar terms were included in the basisset generation and were used to determine the spin-free wavefunctions and energies in the complete active space selfconsistent field (CASSCF) method. ${ }^{47}$ Next, spin-orbit coupling was added within the restricted-active-space state-interaction (RASSI-SO) method, which uses the spin-free wavefunctions as basis states. ${ }^{48,49}$ The resulting wavefunctions and energies are used to compute the magnetic properties and g-tensors of the lowest states from the energy spectrum by using the pseudospin $S=1 / 2$ formalism in the SINGLE_ANISO routine..$^{50,51}$ The dipolar interactions and $J$ constants are investigated using the POLY_ANISO software, the interaction Hamiltonian is built on the basis of the ground-state doublet of each Dy III center. ${ }^{34,52}$ Cholesky decomposition of the bielectronic integrals was employed to save disk space and speed-up the calculations. ${ }^{53}$ The active space of the self-consistent field (CASSCF) method consisted of the nine $4 f$ electrons of the Dy"l' ion spanning the seven $4 f$ orbitals, i.e. CAS $(9,7) S C F$. State-averaged CASSCF calculations were performed for all of the sextets ( 21 roots), all of the quadruplets (224 roots), and 300 out of the 490 doublets (due to software limitations) of the Dy'll ion. 21 sextets, 128 quadruplets, and 107 doublets were mixed through spin-orbit coupling in RASSI-SO. All atoms were described by ANO-RCC basis sets. ${ }^{54-56}$ The following contractions were used: [8s7p4d3f2g1h] for Dy atoms, [7s6p4d2f] for Y atoms, [4s3p2d] for $\mathrm{O}$ atoms, [3s2p] for $\mathrm{C}$ atoms, [4s3p] for $\mathrm{S}$ atoms and [2s] for $\mathrm{H}$ atoms.

To give more insights on the orientation of the magnetic axis, the molecular electrostatic potential is calculated from the $a b$ initio LOPROP charge analysis ${ }^{27}$, using the home-made CAMMEL code (Calculated Molecular Multipolar Electrostatics), following:

$$
V\left(r_{i}\right)=\sum_{i}^{N} \frac{q_{i}}{\left|r_{i}-r\right|}+\frac{p_{i} \cdot r_{i}}{\left|r_{i}-r\right|^{3}}+\frac{r_{i} \cdot\left(Q_{i} \times r_{i}\right)}{\left|r_{i}-r\right|^{5}}
$$

where $q_{i}, p, Q_{i}$ and $r_{i}$ are respectively the charge, dipole and quadrupole moments and displacement vector of the i-th atom. The potential is drawn on a sphere defined by the user around the central lanthanide ion. For a clearer representation of the potential, the intensity can be directly related to both the color (red $=$ high potential and blue $=$ low potential) and the height of the irregularities. Our software enables also to plot the contribution of each component to the total molecular potential. This program has already been used in previous works to give some hints on the orientation of magnetization. ${ }^{28,29}$

The dipole-dipole interaction ${ }^{55}$ between two magnetic centers 1 and 2 , bearing the magnetic moment $\mu_{1}$ and $\mu_{2}$ respectively, is described as

$$
H_{\text {dip }}=-\frac{1}{R_{12}^{3}} \mu_{1} \cdot \mu_{2}-3\left(\mu_{1} \cdot \vec{r}_{12}\right)\left(\mu_{2} \cdot \vec{r}_{12}\right)
$$

where $R_{12}$ corresponds to the distance between the magnetic centers and $\vec{r}_{12}$ stands for the unit vector along the 12 direction.

\section{Conflicts of interest}

There are no conflicts to declare.

\section{Acknowledgements}

This work was supported by the CNRS, Université de Rennes 1, Agence Nationale de la Recherche ( ${ }^{\circ}$ ANR-13-BS07-0022-01), France-Russia MULTISWITCH PRC Grant (N²27606), the European Commission through the ERC-CoG 725184 MULTIPROSMM (project n. 725184) and the Russian Foundation for Basic Research (grant 19-53-15007 NCNI_a). B.L.G. and V.M. thank the French GENCI/IDRIS-CINES centres for high-performance computing resources.

\section{Notes and references}

1 R. Sessoli, D. Gatteschi, A. Caneschi and M. Novak, Magnetic bistability in a metal-ion cluster, Nature, 1993, 365, 141-143.

2 M. Mannini, F. Pineider, P. Sainctavit, C. Danieli, E. Otero, C. Sciancalepore, A. M. Talarico, M.-A. Arrio, A. Cornia, D. Gatteschi and S. Sessoli, Magnetic memory of a singlemolecule quantum magnet wired to a gold surface, Nat. Mater., 2009, 8, 194-197.

3 S. Thiele, F. Balestro, R. Ballou, S. Klyatskaya, M. Ruben and W. Wernsdorfer, Electrically driven nuclear spin resonance in single-molecule magnets, Science, 2014, 344, 1135-1138.

4 K. S. Pedersen, A.-M. Ariciu, S. McAdams, H. Weihe, J. Bendix, F. Tuna and S. Piligkos, Toward Molecular $4 \mathrm{f}$ Single-lon Magnet Qubits, J. Am. Chem. Soc., 2016, 138, 5801-5804.

5 (a) F.-S. Guo, B.-M. Day, Y.-C. Chen, M.-L. Tong, A. Mansikkamäki, and R. A. Layfield, A Dysprosium Metallocene Single-Molecule Magnet Functioning at the Axial Limit, Angew. Chem., Int. Ed., 2017, 56, 11445-11449; (b) C. A. P. Goodwin, F. Ortu, D. Reta, N. F. Chilton and D. P. Mills, Molecular magnetic hysteresis at 60 kelvin in dysprosocenium, Nature, 2017, 548, 439-442; (c) K. R. McClain, C. A. Gould, K. Chakarawet, S. J. Teat, T. J. Groshens, J. R. Long and B. G. Harvey, High temperature magnetic blocking and magneto-structural correlations in a series of dysprosium(iii) metallocenium single-molecule magnets, Chem. Sci., 2018, 9, 8492-8503; (d) F.-S. Guo, B.-M. Day, Y.-C. Chen, M.-L. Tong, A. Mansikkamäki and R. A. Layfield, Magnetic hysteresis up to 80 kelvin in a dysprosium metallocene single-molecule magnet, Science, 2018, 362, 1400-1403.

6 (a) O. Sato, Dynamic molecular crystals with switchable physical properties, Nat. Chem., 2016, 8, 644-656; (b) 0. Cador, B. Le Guennic and F. Pointillart, Electro-activity and magnetic switching in lanthanide-based single-molecule magnets, Inorg. Chem. Front. 2019, 6, 3398-3417.

7 D.-Q. Wu, D. Shao, X.-Q. Wei, F.-X. Shen, L. Shi, D. Kempe, Y.Z. Zhang, K. R. Dunbar and X.-Y. Wang, Reversible On-Off Switching of a Single-Molecule Magnet via a Crystal-to-Crystal Chemical Transformation, J. Am. Chem. Soc., 2017, 139, 11714-11717.

8 J. Vallejo, E. Pardo, M. Viciano-Chumillas, I. Castro, P. Amoros, M. Déniz, C. Ruiz-Pérez, C. Yuste-Vivas, J. Krzystek, M. Julve, M. Lloret and J.; Cano, Reversible solvatomagnetic switching 
in a single-ion magnet from an entatic state, Chem. Sci., 2017, 8, 3694-3702.

9 D. Pinkowicz, M. Ren, L.-M. Zheng, S. Sato, M. Hasegawa, M. Morimoto, M. Irie,B. K. Breedlove, G. Cosquer, K. Katoh and M. Yamashita, Control of the Single-Molecule Magnet Behavior of Lanthanide-Diarylethene Photochromic Assemblies by Irradiation with Light, Chem. Eur. J., 2014, 20, 12502-12513.

10 (a) I.-R. Jeon, L. Sun, B. P. Negru, R. Van Duyne, M. Dinca and T. David Harris, Solid-State Redox Switching of Magnetic Exchange and Electronic Conductivity in a BenzoquinoidBridged Mn" Chain Compound, J. Am. Chem. Soc., 2016, 138, 6583-6590; (b) S. Fortier, J. J. Le Roy, C.-H. Chen, V. Vieru, M. Murugesu, L. F. Chibotaru, D. J. Mindiola and K. G. Caulton, A Dinuclear Cobalt Complex Featuring Unprecedented Anodic and Cathodic Redox Switches for Single-Molecule Magnet Activity, J. Am. Chem. Soc., 2013, 135, 14670-14678; (c) G. N. Newton, S. Yamashita, K. Hasumi, J. Matsuno, N. Yoshida, M. Nihei, T. Shiga, M. Nakano, H. Nojiri, W. Wernsdorfer and H. Oshio, Redox-Controlled Magnetic $\left\{\mathrm{Mn}_{13}\right\}$ Keggin Systems, Angew. Chem. Int. Ed., 2011, 50, 5716-5720; (d) M. Gonidec, E. S. Davies, J. McMaster, D. B. Amabinino and J. Veciana, Probing the Magnetic Properties of Three Interconvertible Redox States of a Single-Molecule Magnet with Magnetic Circular Dichroism Spectroscopy, J. Am. Chem. Soc., 2010, 132, 1756-1757; (e) L. Norel, M. Feng, K. Bernot, T. Roisnel, T. Guizouarn, K. Costuas and S. Rigaut, Redox Modulation of Magnetic Slow Relaxation in a $4 \mathrm{f}$-Based Single-Molecule Magnet with a 4d Carbon-Rich Ligand, Inorg. Chem., 2014, 53 2361-2363; (f) C. M. Dickie, A. L. Laughlin, J. D. Wofford, N. S. Bhuvanesh and M. Nippe, Transition metal redox switches for reversible "on/off" and "slow/fast" single-molecule magnet behaviour in dysprosium and erbium bis-diamidoferrocene complexes, Chem. Sci., 2017, 8, 8039-8049; (g) B. Lefeuvre, J. Flores Gonzalez, F. Gendron, V. Dorcet, F. Riobé, V. Cherkasov, O. Maury, B. Le Guennic, O. Cador, V. Kuropatov and F. Pointillart, Redox-Modulations of Photophysical and SingleMolecule Magnet Properties in Ytterbium Complexes Involving Extended-TTF Triads, Molecules, 2020, 25, 492506.

11 (a) B. S. Dolinar, S. Gomez-Coca, D. I. Alexandropoulos and K. R. Dunbar, An air stable radical-bridged dysprosium single molecule magnet and its neutral counterpart: redox switching of magnetic relaxation dynamics, Chem. Commun., 2017, 53, 2283-2286; (b) P. Zhang, M. Perfetti, M. Kern, P. P. Hallmen, L. Ungur, S. Lenz, M. R. Ringenberg, W. Frey, H. Stoll, G. Rauhut and J. van Slagaren, Exchange coupling and single molecule magnetism in redox-active tetraxolene-bridged dilanthanide complexes, J. Chem. Sci., 2018, 9, 1221-1230.

12 (a) T. T. da Cunha, J. Jung, M.-E. Boulon, G. Campo, F. Pointillart, C. L. M. Pereira, B. Le Guennic, O. Cador, K. Bernot, F. Pineider, S. Golhen and L. Ouahab, Magnetic Poles Determinations and Robustness of Memory Effect upon Solubilization in a Dy"l'-Based Single on Magnet, J. Am. Chem. Soc., 2013, 135, 16332-16335; (b) F. Pointillart, B. Le Guennic, S. Golhen, O. Cador and L. Ouahab, Slow magnetic relaxation in radical cation tetrathiafulvalene-based lanthanide(III) dinuclear complexes, Chem. Commun., 2013, 49, 1163211634; (c) F. Pointillart, B. Le Guennic, O. Cador, O. Maury and L. Ouahab, Lanthanide Ion and Tetrathiafulvalene-Based Ligand as a "Magic" Couple toward Luminescence, Single Molecule Magnets, and Magnetostructural Correlations, Acc. Chem. Res., 2015, 48, 2834-2842.

13 F. Pointillart, S. Klementieva, V. Kuropatov, Y. Le Gal, S Golhen, O. Cador, V. Cherkasov and L. Ouahab, A single molecule magnet behaviour in a D3h symmetry Dy(III) complex involving a quinone-tetrathiafulvalene-quinone bridge, Chem. Commun., 2012, 48, 714-716.
14 N. O. Chalkov, V. K. Cherkasov, G. A. Abakumov, G. V. Romanenko, S. Y. Ketkov, I. V. Smolyaninov, A. G. Starikov and V. A. Kuropatov, Compactly Fused o-Quinone-Extended Tetrathiafulvalene-o-Quinone Triad - a Redox-Amphoteric Ligand, Eur. J. Org. Chem., 2014, 4571-4576.

15 M. Llunell, D. Casanova, J. Cirera, J. M. Bofill, P. Alemany and S. Alvarez, SHAPE (version 2.1), Barcelona, 2013.

16 A. E. Jones, C. A. Christensen, D. F. Perepichka, A. S. Batsanov, A. Beeby, P. J. Low, M. R. Bryce and A W. Parker, Photochemistry of the $\pi$-Extended 9,10-Bis(1,3-dithiol-2ylidene)-9,10-dihydroanthracene System: Generation and Characterisation of the Radical Cation, Dication, and Derived Products, Chem. Eur. J., 2001, 7, 973-978.

17 W. F. Cooper, J. W. Edmonds, F. Wudl and P. Coppens, The 22-bi-1,3-dithiole, Cryst. Struct. Commun., 1974, 3, 23.

18 A. Ellern, J. Bernstein, J. Y. Becker, S. Zamir, L. Shahal and S. Cohen, A New Polymorphic Modification of Tetrathiafulvalene. Crystal Structure, Lattice Energy and Intermolecular Interactions, Chem. Mater., 1994, 6, 13781385.

19 (a) F. Pointillart, Y. Le Gal, S. Golhen, O. Cador and L. Ouahab, Single-Molecule Magnet Behaviour in a TetrathiafulvaleneBased Electroactive Antiferromagnetically Coupled Dinuclear Dysprosium(III) Complex, Chem. Eur. J., 2011, 17, 1039710404; (b) X. Yi, K. Bernot, O. Cador, J. Luzon, G. Calvez, C. Daiguebonne and $\mathrm{O}$. Guillou, Influence of ferromagnetic connection of Ising-type Dy"l'-based single ion magnets on their magnetic slow relaxation, Dalton Trans., 2013, 42, 67286731; (c) F.-S. Guo and R. A. Layfield, Strong direct Exchange coupling and single-molecule magnetism in indigo-bridged lanthanide dimers, Chem. Commun., 2017, 53, 3130-3133; (d) H Tian, B.-L. Wang, J. Lu, H.-T. Liu, J. Su, D. Li and J. Dou, Consecutive one-/two-step relaxation transformations of single-molecule magets via coupling dinuclear dysprosium compounds with chloride bridges, Chem. Commun., 2018, 54, 12105-12108; (e) L. Zhang, Y.-Q. Zhang, P. Zhang, L. Zhao, M. Guo and J.; Tang, Single-Molecule Magnet Behavior Enhanced by Synergic Effect of Single-Ion Anisotropy and Magnetic Interactions, Inorg. Chem., 2017, 56, 7882-7889; (f) M. J. Giansiracusa, E. Moreno-Pineda, R. Hussain, R. Marx, M. Martinez Prada, P. Neugebauer, S. Al-Badran, D. Collison, F. Tuna, J. van Slageren, S. Carretta, T. Guidi, E. J. L. McInnes, R. E. Winpenny and N. F. Chilton, Measurement of Magnetic Exchange in Asymmetric Lanthanide Dimetallics: Toward a Transferable Theoretical Framework. J. Am. Chem. Soc., 2018, 140, 2504-2513.

20 (a) F. Luis, M. J. Martinez-Pérez, O. Montero, E. Coronado, S. Cardona-Serra, C. Marti-Gastaldo, J.-M.. Clemente-Juan, J. Sesé, D. Drung and T. Schurig, Spin-lattice relaxation via quantum tunneling in an $\mathrm{Er}^{3+}$-polyoxometalate molecular magnet, Phys. Rev. B, 2010, 82, 060403; (b) F. Pointillart, K. Bernot, S. Golhen, B. Le Guennic, T. Guizouarn, L. Ouahab and O. Cador, Magnetic memory in an isotopically enriched and magnetically isolated mononuclear dysprosium complex, Angew. Chem. Int. Ed., 2015, 54, 1504-1507; (c) Y. Kishi, F. Pointillart, B. Lefeuvre, F. Riobé, B. Le Guennic, S. Golhen, O. Cador, O. Maury, H. Fujiwara and L. Ouahab, Isotopically enriched polymorphs of dysprosium single molecule magnets, Chem. Commun., 2017, 53, 3575-3578; (d) E. Moreno-Pineda, M. Damjanovic, O. Fuhr, W.Wernsdorfer and M. Ruben, Nuclear Spin Isomers: Engineering a $\mathrm{Et}_{4} \mathrm{~N}\left[\mathrm{DyPC}_{2}\right]$ Spin Qudit, Angew. Chem., Int. Ed., 2017, 56, 9915-9919; (e) Y.-C. Chen, J.L. Liu, W. Wernsdorfer, D. Liu, L F. Chibotaru, X-M. Chen and M.-L. Tong, Hyperfine-Interaction-Driven Suppression of Quantum Tunneling at Zero Field in a Holmium(III) Single-lon Magnet, Angew. Chem., Int. Ed., 2017, 56, 4996-5000; (f) J. Flores Gonzalez, F. Pointillart and O. Cador, Hyperfine coupling and slow magnetic relaxation in isotopically enriched 
DyIII mononuclear single-molecule magnets, Inorg. Chem. Front., 2019, 6, 1081-1086.

21 X. Zhang, S. Liu, V. Vieru, N. Xu, C. Gao, B. W. Wang, W. Shi, L. F.. Chibotaru, S. Gao, P. Cheng and A. K. Powell, Coupling Influences SMM Properties for Pure $4 \mathrm{f}$ Systems, Chem. Eur. J., 2018, 24, 6079-6086.

22 (a) P.-E. Car, M. Perfetti, M. Mannini, A. Favre, A. Caneschi and R. Sessoli, Giant field dependence of the low temperatura relaxation of the magnetization in a dysprosium(III)-DOTA complex, Chem. Commun., 2011, 47, 3751-3753; (b) J.-K. OuYang, N. Saleh, G. Fernandez Garcia, L. Norel, F. Pointillart, T. Guizouarn, O. Cador, F. Totti, L. Ouahab, J. Crassous and B. Le Guennic, Improved slow magnetic relaxation in optically pure helicene-based Dy"lI single molecule magnets, Chem. Commun., 2016, 52, 14474-14477.

23 R. Orbach, Spin-lattice relaxation in rare-earth salts, Proc. $R$. Soc. Lond. A, 1961, 264, 458-484.

24 A. Abragam and B. Bleaney, B. Electron Paramagnetic Resonance of Transition lons, Clarendon Press. Oxford, 1970.

25 A. Singh and K. N. Shrivastava, Optical-acoustic two-phonon relaxation in spin systems, Phys. Status Solidi B, 1979, 95, 273277; K. N. Shirivastava, Theory of Spin-Lattice Relaxation, Phys. Status Solidi B, 1983, 177, 437-458.

26 J. Tang and P. Zhang, P. Lanthanide Single Molecule Magnets; Springer, 2015.

27 L. Gagliardi, R. Lindh and G.; Karlström, Local properties of quantum chemical systems: The LoProp approach, J. Chem. Phys., 2004, 121, 4494.

28 K. Zhang, V. Montigaud, O. Cador,G.-P. Li, B. Le Guennic, J. Tang, Y. Y. Wang, Tuning the Magnetic Interactions in Dy(III)4 Single-Molecule Magnets, Inorg. Chem., 2018, 57, 8550-8557.

29 G. Huang, G. Fernandez-Garcia, I. Badiane, M. Camarra, S. Freslon, O. Guillou, C. Daiguebonne, F. Totti, O. Cador, T. Guizouarn, B. Le Guennic and K. Bernot, Magnetic Slow Relaxation in a Metal-Organic Framework Made of Chains of Ferromagnetically Coupled Single-Molecule Magnets, Chem. Eur. J., 2018, 24, 6983-6991.

$30 \mathrm{M}$. Perfetti, Cantilever torque magnetometry on coordination compounds: from theory to experiments, Coord. Chem. Rev., 2017, 348, 171-186

31 I. Mihalcea, M. Perfetti, F. Pineider, L. Tesi, V. Mereacre, F. Wilhelm, A. Rogalev, E. C. Anson, K. A. Powell and R. Sessoli, Spin Helicity in Chain, Inorg. Chem., 2016, 55, 10068-10074.

32 F. Pointillart, J.-K. Ou-Yang, G. Fernandez Garcia, V. Montigaud, J. Flores Gonzalez, R. Marchal, L. Favereau, F. Totti, J. Crassous, O. Cador, L. Ouahab and B. Le Guennic Tetrathiafulvalene-Based Helicene Ligand in the Design of a Dysprosium Field-Induced Single-Molecule Magnet, Inorg. Chem., 2019, 58, 52-56.

33 L. Ungur, M. Thewissen, J.-P. Costes, W. Wernsdorfer and L. F. Chibtaru, Interplay of Strongly Anisotropic Metal lons in Magnetic Blocking of Complexes, Inorg. Chem., 2013, 52, 6328-6337.

34 L. F. Chibotaru, L. Ungur, L. The Computer Programs SINGLE_ANISO and POLY_ANISO. 2006, University of Leuven.

35 N. O. Chalkov, V. K. Cherkasov, G. A. Abakumov, G. A. Stariko and A. V. Kuropatov, Protonated paramagnetic redox forms of di-o-quinone bridged with p-phenylene-extended TTF: A EPR spectroscopy study, Beilstein J. Org. Chem., 2016, 12, 24502456.

36 N. O. Chalkov, V. K. Cherkasov, G. A. Abakumov, A. G. Starikov and V. A. Kuropatov, EPR spectroscopy study of di-o-quinone bridged by $\pi$-extended TTF: redox behaviour and binding modes as a ligand, New J. Chem., 2016, 40, 1244-1249.

37 M. F. Richardson, W. F. Wagner and D. E.; Sands. Rare-earth trishexafluoroacetylacetonates and related compounds, $J$. Inorg. Nucl. Chem., 1968, 30, 1275-1289.
38 G. L. Sheldrick., SHELXT - Integrated space-group and crystalstructure determination, Acta Crystallogr.. Sect. A Found Adv., 2015, 71, 3-8.

39 G. M. Sheldrick, Crystal structure refinement with SHELXL, Acta Crystallogr. Sect. C, 2015, 71, 3-8.

40 A. L. Spek, Single-crystal structure validation with the program PLATON, J. Appl. Crystallogr., 2003, 36, 7-13.

41 M. J. Frisch, G. W. Trucks, H. B. Schlegel, G. E. Scuseria, M. A Robb, J. R. Cheeseman, G. Scalmani, V. Barone, G. A. Petersson, H. Nakatsuji. X. Li. M. Caricato. A. Marenich, J. Bloino. B. G. Janesko. R. Gomperts. B. Mennucci. H. P. Hratchian. J. V. Ortiz. A. F. Izmaylov. J. L. Sonnenberg. D. Williams-Young, F. Ding, F. Lipparini, F. Egidi, J. Goings, B. Peng, A.Petrone, T. Henderson, D. Ranasinghe. V. G. Zakrzewski, J. Gao, N. Rega, G. Zheng, W. Liang, M. Hada, M. Ehara, K. Toyota, R. Fukuda, J. Hasegawa, M. Ishida, T. Nakajima, Y. Honda, O. Kitao, H. Nakai, T. Vreven, K. Throssell, J. A. Montgomery, J. E. Peralta, Jr., F. Ogliaro, M. Bearpark, J. J. Heyd. E. Brothers, K. N. Kudin, V. N. Staroverov, T. Keith, R. Kobayashi, J. Normand, K. Raghavachari, A. Rendell, J. C. Burant, S. S. Iyengar, J. Tomasi, M. Cossi, J. M. Millam. M. Klene, C. Adamo, R. Cammi, J. W. Ochterski, R. L. Martin, K. Morokuma, O. Farkas, J. B. Foresman and D. J. Fox. Gaussian 09. Revision D.01; Gaussian Inc.: Wallingford. CT. 2016.

42 J.P. Perdew, K. Burke and M.; Ernzerhof, Generalized Gradient Approximation, Phys. Rev. Lett., 1996, 77, 3865.

$43 \mathrm{C}$. Adamo and V. Barone, Toward reliable density functional methods without adjustable parameters: The PBEO model, $J$. Chem. Phys., 1999, 110, 6158.

$44 \mathrm{M}$. Dolg, H. Stoll and H. Preuss, A combination of quasirelativistic pseudopotential and ligand field calculations for lanthanoid compounds, Theor. Chim. Acta, 1993, 85, 441450.

45 F. Weigend and R. Ahlrichs, Balanced basis sets of split valence, triple zeta valence and quadruple zeta valence quality for $\mathrm{H}$ to $\mathrm{Rn}$ : Design and assessment of accuracy, Phys. Chem. Chem. Phys., 2005, 7, 3297-3305.

46 F. Aquilante, J. Autschbach, R. K. Carlson, L. F. Chibotaru. M. G. Delcey, L. De Vico, I. F. Galván, N. Ferré, L. M. Frutos, L. Gagliardi, M. Garavelli, A. Giussani, C. E. Hoyer, G. L. Manni, H. Lischka, D.-X. Ma, P. Malmqvist; T. Müller, A. Nenov, M. Olivucci, T. B. Pedersen, D L. Peng, F. Plasser, B. Pritchard, M. Reiher, I. Rivalta, I. Schapiro, J. Segarra-Martí, M. Stenrup, D. G. Truhlar, L. Ungur, A. Valentini, S. Vancoillie, V. Veryazov, V. P. Vysotskiy, O. Weingart, F. Zapata and R. Lindh, MOLCAS 8: New capabilities for multiconfigurational quantum chemical calculations across the periodic table, J. Comput. Chem., 2016, 37, 506-541.

47 B. O. Roos, P. R. Taylor and P. E. M. Siegbahn, A complete active space SCF method (CASSCF) using a density matrix formulated super- $\mathrm{Cl}$ approach, Chem. Phys., 1980, 48, 157173.

48 P. A. Malmqvist, B. O. Roos and B. Schimmelpfennig, The restricted active space (RAS) state interaction with spin-orbit coupling, Chem. Phys. Lett., 2002, 357, 230-240.

49 P. A. Malmqvist and B. O. Roos, The CASSCF state interaction method, Chem. Phys. Lett., 1989, 155, 189-194.

50 L. F. Chibotaru and L. Ungur, ab initio calculation of anisotropic magnetic properties of complexes. I. Unique definition of pseudospin Hamiltonians and their derivation, $J$. Chem. Phys., 2012, 137, 064112.

51 L. F. Chibotaru, L. Ungur and A. Soncini, The origin of nonmagnetic Kramers doublets in the ground state of dysprosium triangles: evidence for a toroidal magnetic moment, Angew. Chem. Int. Ed., 2008, 47, 4126-4129.

$52 \mathrm{~N}$. Iwahara and L. F. Chibotaru, Exchange interaction between J multiplets, Phys. Rev. B., 2015, 91, 174438. 
53 F. Aquilante, P.-A. Malmqvist, T.-B. Pedersen, A. Ghosh. B. O. Roos, Cholesky Decomposition-Based Multiconfiguration Second-Order Perturbation Theory (CD-CASPT2): Application to the Spin-State Energetics of Co'II(diiminato)(NPh), J. Chem. Theory Comput., 2008, 4, 694-702.

54 B. O. Roos, R. Lindh, P.-A. Malmqvist, V. Veryazov and P.-O. Widmark, Main Group Atoms and Dimers Studied with a New Relativistic ANO Basis Set, J. Phys. Chem. A, 2004, 108, 28512858.

55 B. O. Roos, R. Lindh, P.-A. Malmqvist, V. Veryazov and P.-O. Widmark, New Relativistic ANO Basis Sets for Transition Metal Atoms, J. Phys. Chem. A, 2005, 109, 6575-6579.

56 B. O. Roos, R. Lindh, P.-A. Malmqvist, V. Veryazov, P.-O. Widmark and A.-C. Borin, New Relativistic Atomic Natural Orbital Basis Sets for Lanthanide Atoms with Applications to the Ce Diatom and $\mathrm{LuF}_{3}$, J. Phys. Chem. A, 2008, 112, 1143111435. 